\title{
Addressing complexity and uncertainty: conceptual models and expert judgments applied to migratory birds in the oil sands of Canada
}

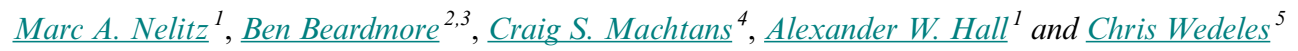

\begin{abstract}
Complexity and uncertainty are inherent in social-ecological systems. Although they can create challenges for scientists and decision makers, they cannot be a reason for delaying decision making. Two strategies have matured in recent decades to address these challenges. Systems thinking, as embodied by conceptual modeling, is a holistic approach in which a system can be better understood by examining it as a whole. Expert elicitation represents a second strategy that enables a greater diversity of inputs to understand complex systems. We explored the use of conceptual models and expert judgments to inform expansion of monitoring around oil sands development in northern Alberta, Canada, particularly related to migratory forest birds. This study area is a complex social-ecological system for which there is an abundance of specific information, but a relatively weak understanding about system behavior. Multiple conceptual models were developed to represent complexity and provide a more fulsome view of influences across the landscape. A hierarchical approach proved useful, and a mechanistic structure of the models clarified the cumulative and interactive nature of factors within and outside the study area. To address gaps in understanding, expert judgments were integrated using a series of structured exercises to derive "weightings" of importance of different components in the conceptual models, specifically pairwise comparisons, Likert scaling, and a maximum difference conjoint approach. These exercises were helpful for discriminating the importance of different influences and illuminating the competing beliefs of experts. Various supporting tools helped us engage a group of experts from across North America, which included a virtual meeting, online polling, desktop sharing, web survey, and financial incentive. This combination of techniques was innovative and proved useful for addressing complexity and uncertainty in a specific natural resource management setting, which can be informative for others facing similar challenges.
\end{abstract}

Key Words: complexity; conceptual modeling; expert judgment; migratory birds; oil sands; uncertainty

\section{INTRODUCTION}

Complexity and uncertainty are inherent in social-ecological systems. Complex systems tend to have a large number of components and a high level of interconnectedness among them often involving nonlinear interactions and feedbacks that ultimately lead to complex behavior. Importantly, observable behaviors emerge as a result of these interactions and are not contained within the individual components alone (WaltnerToews et al. 2008, Cilliers et al. 2013). Uncertainties are also pervasive. There may be an imperfect knowledge about the structure and behavior of a system, large natural variation across locations and years, errors in human observation, varying assumptions in the way data are used to provide broader inferences, and a lack of clarity about how a system should be managed (Suter et al. 1987, Morgan and Henrion 1990). For scientists and decision makers, these realities create challenges for understanding social-ecological systems and managing actions within their control by making it difficult to reliably identify pathways of cause and effect in the presence of large unknowns and confounding factors that are hard to isolate and to which it is hard to assign attribution. Despite these challenges, they cannot be a cause for delaying research and management given the urgent need for making decisions today.

Over recent decades, two strategies have become more widespread, in part, to address these challenges. Though framed in different ways for different purposes, a first strategy is systems thinking, which represents a more holistic approach to improve understanding and management of complex systems (Grant et al. 1997, Meadows 2008). It is based on the premise that the behavior of parts of a system can be better understood by examining it as a whole. Such a perspective underlies the growing interest in cumulative effects when undertaking environmental assessments (Duinker and Greig 2006, Canter and Ross 2010), moving away from single species management of fisheries toward ecosystem-based approaches (Browman and Stergiou 2004) and increasing consideration of current environmental stressors in frameworks for assessing vulnerability to future climate change (Staudt et al. 2013). Expert elicitation represents a second strategy that has seen growing use in situations in which complexities and uncertainties are high and there is the urgent need to make decisions despite these realities (Donlan et al. 2010, McDaniels et al. 2010, Teck et al. 2010, Martin et al. 2012, Wittmann et al. 2015). There are concerns that the judgments of experts can be biased or poorly calibrated (Tversky and Kahneman 1974); however, when these concerns are addressed, expert opinions can prove valuable for estimating model parameters, characterizing uncertainty, validating results from other studies, and filling knowledge gaps for decision making (Martin et al. 2012). In the context of complexity and uncertainty, systems thinking encourages a greater diversity of considerations to represent complex systems, whereas the consideration of expert judgments enables the inclusion of both "hard" forms of knowledge, i.e., based on scientific methods of observation and analysis, and "soft" forms of knowledge, i.e., based on individual judgments, priorities, and values, when faced with imperfect information.

Analytical approaches that explicitly involve systems thinking and expert judgments are embodied in various participatory modeling techniques (Lynam et al. 2007, Gray et al., in press). These

${ }^{1}$ ESSA Technologies Ltd., ${ }^{2}$ Beardmore Consulting LLC, ${ }^{3}$ Wisconsin Department of Natural Resources, ${ }^{4}$ Canadian Wildlife Service, Environment Canada, ${ }^{5}$ ArborVitae Environmental Services Ltd. 
approaches have in common a tendency to use conceptual models coupled with existing evidence and expert/stakeholder input to characterize the components and linkages in the particular system of interest. Individual approaches vary in the way they characterize relationships with varying levels of sophistication. Approaches range from conceptual models that provide qualitative representations of ecosystem interactions (DiGennaro et al. 2012), to semiquantitative approaches such as fuzzy cognitive mapping, which uses fuzzy logic to assign directions of influence and weights to relationships (Papageorgiou and Kontogianni 2012), to Bayesian belief networks, which use empirically or expert-derived probability distributions around interacting variables and their states of nature to provide probabilistic predictions of outcomes (Marcot et al. 2001).

In our experience, there can be limitations in applying such techniques in some situations. For instance, although these approaches provide a strong framework for encouraging a mechanistic representation of how a system functions, they can be limited in their ability to allow experts to quantify linkages based on a more holistic understanding of pathways within a system. Many field studies and experts' mental models are based on knowledge derived from empirical relationships that tend to embed many individual linkages into more fulsome pathways of effect (Rastetter et al. 2003, Shochat et al. 2006). Thus, it can be helpful to elicit expert judgments in a more holistic way rather than a more reductionist approach that forces consideration of only a few individual components in isolation of interactions with other components. One approach to address this limitation is to use structured exercises in combination with a clear foundation of technical information. Through closed-ended questions, researchers can elicit standardized information from participants, thereby facilitating the combination of responses from several individuals (Hofer 1986) while still allowing them to make intuitive judgments about the system as a whole. In addition, multiattribute methods derived from the field of choice modeling allow analysts to jointly estimate parameters for individual components from more holistic evaluations (Louviere et al. 2000), adding value to box-arrow conceptual models by supplying numeric weights on the same interval scale (Flynn et al. 2007).

We explore the approaches and limitations, alongside the opportunities and challenges, of applying conceptual modeling and expert elicitation as ways of addressing complexity and uncertainty in a specific natural resource setting. In particular, we discuss the strategies and outcomes around conceptual model development that helped clarify understanding of the multiple and interacting influences of different human stressors on a guild of interest, migratory forest birds. We then discuss the elicitation strategies and information outputs derived from technical experts that helped strengthen the understanding of importance of different influences in the conceptual models. The ultimate objective of this research was to guide design and expansion of monitoring programs in northern Alberta, Canada, where it is important to understand the impacts of oil sands development on biodiversity (Gosselin et al. 2010, Environment Canada 2011, GOC 2012).

\section{METHODS}

The area of interest for this case study represents a complex socialecological system in the boreal forest of northern Alberta, Canada
(Fig. 1). Human activities include approximately $142,000 \mathrm{~km}^{2}$ of oil sands deposits, as well as conventional oil and gas deposits, commercial forestry, agriculture, urbanization, a transportation network to support those industries, and other smaller economic interests (see Table A1.1 in Appendix 1). Large-scale and natural drivers such as an active fire regime, insect disturbance, and climate change also have an overarching influence. A rich biodiversity of terrestrial and freshwater species live in this landscape.

Fig. 1. Study area boundary for the joint oil sands monitoring program (dashed line) and oil sand lease (solid line) areas in northern Alberta, Canada.

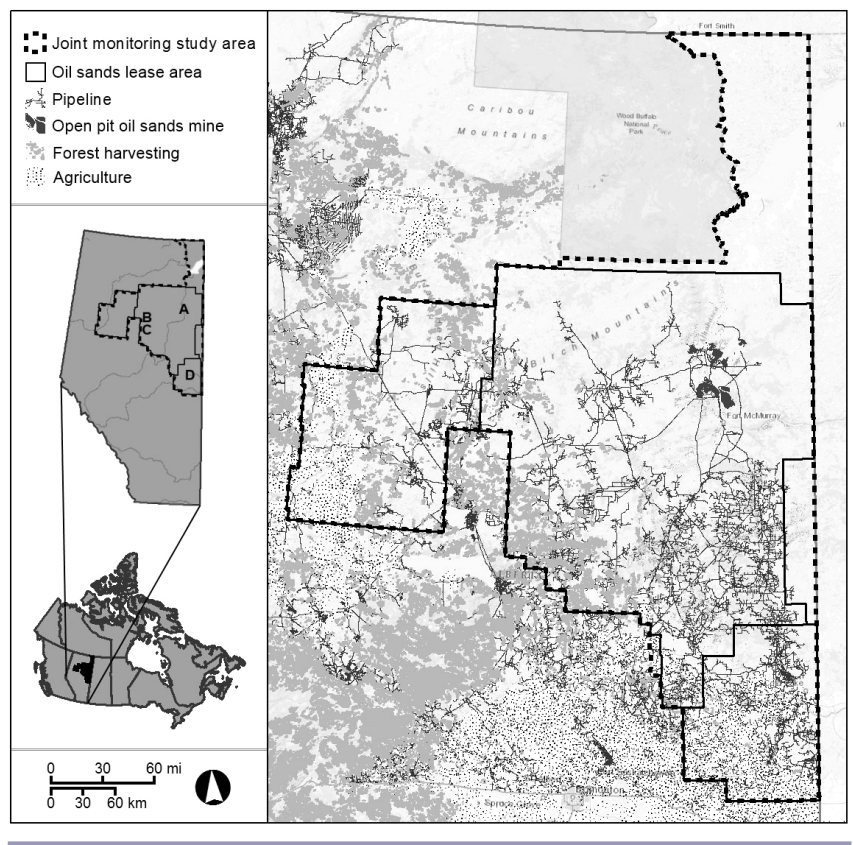

\section{Conceptual model development}

We began development of conceptual models with a literature review to identify key features and types of approaches to suit our needs. We selected model types that would best serve the various audiences, systems and processes of interest, levels of specificity, and information availability. To represent the complexity of the study area, we developed conceptual models at a hierarchy of scales ranging from ecosystem to landscape to guild to species levels. There was an intentional decrease in breadth and increase in specificity in these models moving from highest to lowest levels in the hierarchy. Models were developed with the intention of being both independent and interdependent with others such that higher level models informed lower level models.

Conceptual models were developed in five steps based on guidance from others (see Fig. 2; Grant et al. 1997, Noon 2002, Fischenich 2008). First, model objectives were clarified based on intended uses and audiences, which ranged from knowledgeable decision makers to ecologists and avian specialists. Next, models were bounded according to subsystems of interest and related spatial/temporal boundaries, which required clarifying the focus and level of specificity for each model. This clarity included understanding the development sectors, human activities, 
stressors, natural drivers, and valued ecosystem components represented in each model. A third step required specifying model components, in particular, summarizing the evidence pertaining to the drivers, outcomes, and linkages at relevant scales. Drivers included natural influences and human stressors that affect the behavior or state of the ecosystems' components. Outcomes included the direct and indirect results, impacts, or consequences of particular drivers. Linkages represented the connections between drivers and outcomes, such that each linkage was associated with an "effect," and a series of linkages from an initial driver to a final outcome was considered a "pathway of effect." The fourth step included illustrating relationships among the drivers, outcomes, and linkages at each level in the hierarchy to develop graphical representations of each system. All models were mechanistic in nature to illustrate the sequence of causal linkages or pathways of effect between a driver and an outcome of interest. Finally, models were evaluated in several stages for comprehensiveness, consistency, robustness, and importance of components. These evaluation stages involved a combination of internal and external peer review, resulting in many iterations of the models to address the breadth and/or depth required. More details around conceptual model development are available in Appendix 1.

Fig. 2. Overview of activities for conceptual model development and expert engagement as related to modelbuilding phases and level of model complexity.

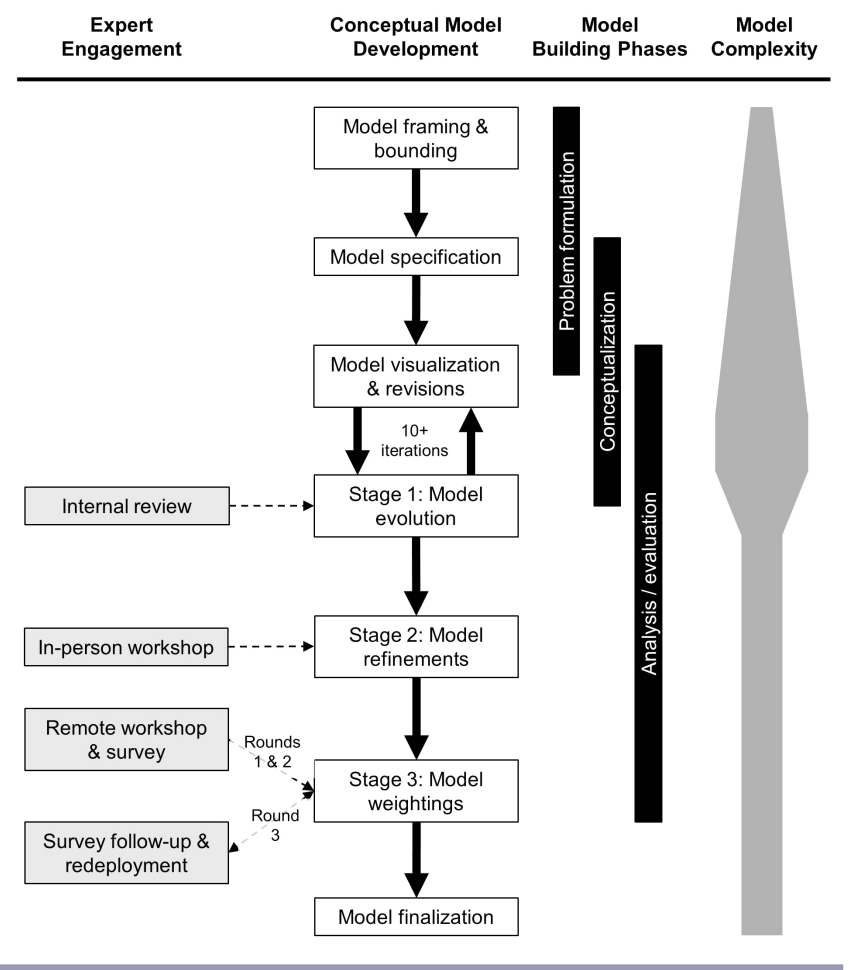

\section{Engagement of technical experts}

The first stages of conceptual model development were based on a review of readily available evidence describing the study area, in other words "hard" forms of knowledge. To effectively leverage and value the collective intelligence of experts, or "soft" forms of knowledge, we intentionally designed a process that engaged scientists in the advanced stages of model development to review, validate, refine, and develop "weightings" of importance around different components in the conceptual models.

To do so, we employed a variety of engagement strategies across model development stages (Fig. 2). A first point of input involved an internal review to refine and validate the models by experts who were avian ecologists internal to the government agency providing input to the broader monitoring program, yet naive to our model-building process. Next, a 2-day in-person workshop was convened to provide a "peer review" to improve the accuracy, relevance, and clarity of the models, as well as to provide guidance on developing a structured survey for eliciting judgments from scientists. Approximately 30 avian experts and ecologists from across North America were initially considered to participate in this research. These experts were from academia and government and had familiarity with conceptual modeling, monitoring, migratory birds, oil and gas development, other development impacts relevant to forest birds, or a combination thereof. We excluded industry representatives purposely given criticisms of influence noted by previously published reviews that have highlighted monitoring shortcomings in the oil sands area. The workshop was attended by 12 external experts. A background document that described the context for the work and conceptual models was distributed in advance of the workshop. Finally, a 1day remote workshop was convened using a conference call, desktop sharing, and live online survey tools to engage 8 experts. These participants included avian experts and ecologists from academia, government, and nongovernmental organizations, many of whom had participated in the earlier in-person workshop. A financial incentive was offered to encourage participation and compensate experts for their time. A background document describing the meeting task process, forest bird model, and its components was distributed prior to the workshop. An overview of materials and an explanation of survey questions were provided at the meeting.

In advance of the remote workshop, a survey was developed as a structured process for eliciting expert judgments on the importance of different components and pathways of effect in the forest bird conceptual model. Prior to its deployment, the survey was piloted with two independent experts to test for clarity and accuracy in framing the questions. The survey was deployed using a uniquely designed website, given the need to provide access to and present a variety of complex technical information, as well as to quickly summarize results for immediate discussion during the workshop.

The survey was completed in three parts and consisted of five sections, incorporating several tools to enable participation, for instance closed-ended questions, the Delphi method, and "fistto-five" voting. It was deliberately organized in a way that required respondents to consider increasing levels of specificity from broad to specific influences on migratory birds. The first part required participants to indicate their familiarity with boreal ecology, both across Canada and in the oil sands area; the sectors of development impacting the region; and five major guilds of forest birds, using a five-point scale from not at all familiar to extremely familiar. These questions were posed to assess the experience of the group and were deployed before engaging the group in the remote workshop. 
The second part of the survey was completed during the remote workshop and focused on understanding the relative importance of breeding, migrating, and overwintering life stages to support regional population abundance and distribution of forest birds in the study area. These questions were posed to provide a better context for understanding the influence of impacts on the breeding range, the area of focus for monitoring and over which agencies have some degree of management control, relative to other life stages where no monitoring would occur and over which agencies have little influence. The relative importance of life stages was assessed using the analytical hierarchy process (AHP), which required presenting all pairwise comparisons of life stages and then asking experts to indicate which are more important and the degree of importance using a standardized five-point scale, ranging from equally important to extremely more important (Pavlikakis and Tsihrintzis 2003). Responses from multiple experts were combined by calculating the geometric mean of importance for each pair across all respondents. Expert ratings were then entered into a pairwise comparison matrix to facilitate calculation of weightings for each individual life stage. This part of the survey also included assessing the relative importance of 19 stressors that were identified as having a potential impact on quality of breeding habitats. These ratings were made using a 5point importance scale, ranging from not at all important to extremely important.

The last part of the survey asked participants to rank the relative importance of each of 16 pathways of effect. Given the complexity of this task, we applied a maximum difference conjoint approach (MDC; Finn and Louviere 1992). Like AHP, the MDC is an iterative approach; however, it relies on experimental design principles to reduce the burden on respondents. With this approach, respondents were asked to identify the pathways they considered to be most and least important from 16 sets of 4 pathways. To ensure the independence of each parameter estimate, each combination of pathways was determined by an experimental design (Raktoe et al. 1981). To reduce the possibility of biases associated with learning or fatigue effects (Louviere et al. 2000), the order of questions was randomly assigned to each participant.

Statistical analysis of MDC surveys is grounded in random utility theory (McFadden 1974), which assumes that people choose the single option that maximizes their benefits. Under this assumption, the probability of an individual choosing one option (i) from a set of alternatives may follow a multinomial logit (MNL) function (Louviere and Woodworth 1983). In the case of the MDC, the choice probability of the least important pathway is assumed to be inversely related to its benefits (Cohen 2003). The resulting statistical model estimates underlying preferences by comparing each particular attribute value relative to a specified base. In our case, effects coding was used to center the resulting parameters around a mean of zero (Bech and Gyrd-Hansen 2005). The resulting model provided preference estimates on an interval scale for each pathway with constants accounting for the effect of list order (Cohen 2003).

The MDC portion of the survey was administered using the Delphi method (Linstone and Turoff 2002), in which experts were first asked to independently respond to a set of structured questions. Data were analyzed in real time with the group convened on the phone shortly afterward to review results and encouraged to share with others why and how they answered the questions. They were then asked to break away again to review their initial responses and allowed to adjust them based on what was heard from others.

Through this process, the experts identified two distinct types of pathways in the conceptual models that were not originally framed as such: pathways by which forest bird habitats are disturbed by various forms of human development and causal mechanisms related to the ecological responses of forest birds to habitat pressures. To address this feedback, additional questions were developed with responses completed approximately two weeks later. These additional questions required experts to rate the strength of influence and certainty of evidence related to the causal mechanisms underlying each of eight habitat pathways of effect. For each pathway, causal mechanisms were rated using five-point scales to represent the strength of influence, ranging from none to dominant, and certainty of evidence related to understanding the causal mechanism, which was rated as theoretically a concern, evidence is ambiguous, evidence is preliminary, evidence is strong, or widespread agreement. Across all parts of the survey, a fist-to-five voting system was used to gauge the level of agreement around the emerging responses from the group, with a fist representing a vote of no support and five fingers representing the strongest level of support.

\section{RESULTS}

\section{Conceptual models}

Fourteen conceptual models were developed at a hierarchy of scales to represent the complexity of the system: one ecosystem, two landscape, two bird guild, and nine species models. A systems model was used for the ecosystem level to illustrate the breadth of human stressors and natural drivers that influence the study area. A state and transition model was used for the landscape level to represent habitat states and transitional processes that influence habitat dynamics, whereas a life cycle model was used to represent population dynamics for the migratory and resident terrestrial species occupying the study area. Life cycle models were also used for the guild and species levels to represent interactions between the environment and all forest and wetland dependent birds that migrate annually from or through the study area. We focus on results related to the forest bird, i.e., guild-level, model because it provided the foundation for the structured survey exercises and determination of model weightings. Other models are provided in Appendix 1.

The forest bird model is provided in Figure 3. The top left portion shows an annual life cycle separated into key life stages: breeding, fall migration, overwintering, and spring migration. An inner ring represents the period until juveniles start breeding. An outer ring represents adult years of life with seven distinct aspects: fecundity, summer growth/condition, summer survival, fall migration survival, overwinter condition, overwinter survival, and spring migration survival. Survival and fecundity have direct influences on populations (arrows to the center), whereas changes in condition have indirect influences through their effect on subsequent life stages (arrows to other life stages). For instance, 
Fig. 3. Conceptual model representing relationships among human stressors, natural drivers, impacts, life stages, and population responses for all forest birds occupying the study area.

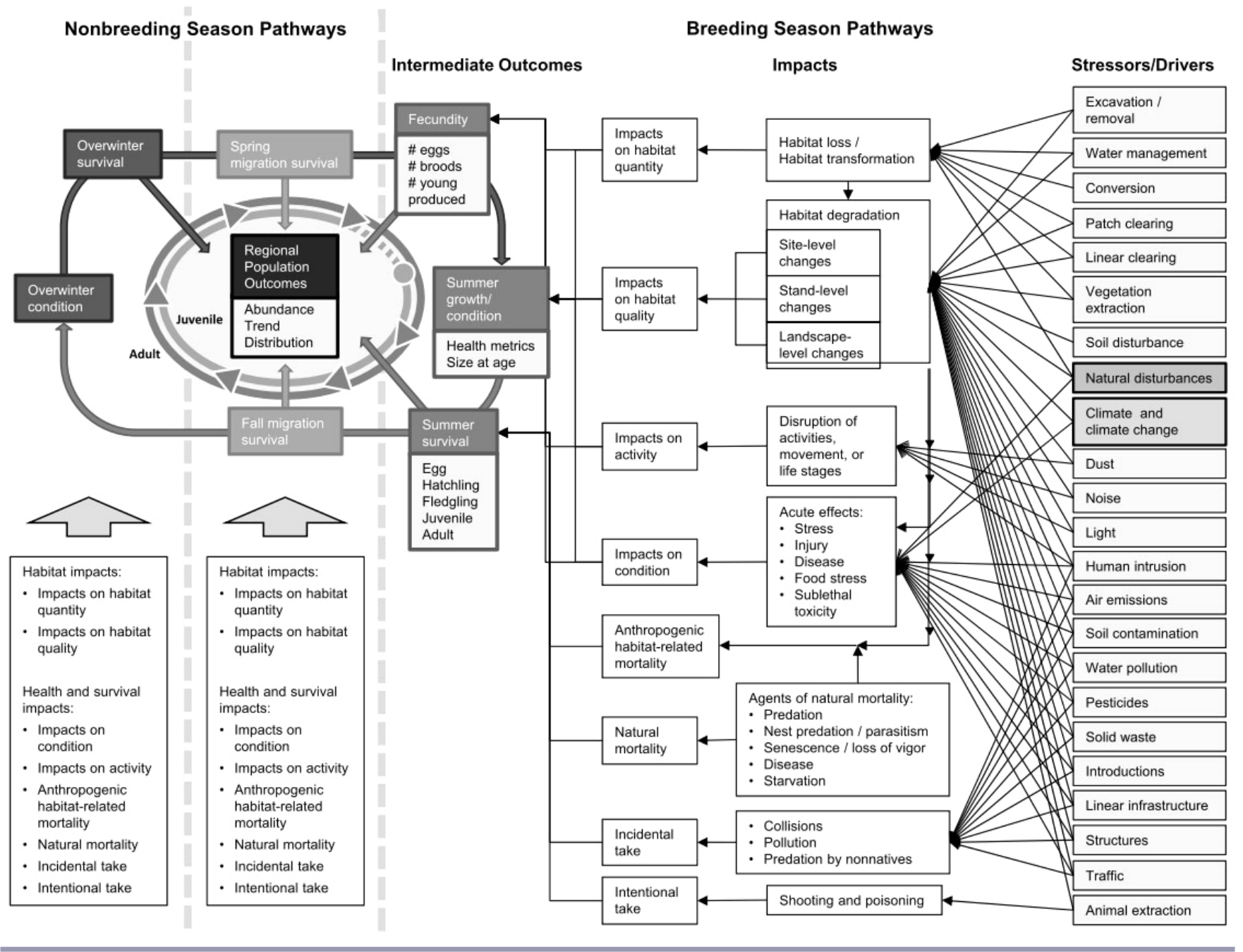

summer growth/condition affects summer survival, fall migration survival, and ultimately overwinter condition (denoted by arrow from summer growth to overwinter condition). Alternatively, fecundity is influenced both by the condition that birds are in when they return from overwintering and conditions on the breeding grounds themselves. Regional population outcomes, as opposed to continental outcomes, are the end points of interest because many migratory species have wide summer breeding ranges that are subject to different stressors in the boreal forest. Human stressors and natural drivers are illustrated in the right portion of the model. These influences have the potential for impacts on summer breeding, migration, and overwintering as mediated by pathways resulting from impacts on habitat, health, and behavior.

Broadscale monitoring is intended to provide information on the role and relative influence of various forcings on migratory birds: mining, forestry, agriculture, urbanization, and conventional oil and gas development, alongside oil sands development and an extensive transportation network to support these sectors. To facilitate this understanding, we adapted the International Union for Conservation of Nature threats classification system (Salafsky et al. 2008) to develop a list of 19 stressors as the fundamental agents of change in the study area (right side of Fig. 3, described in Table A1.3 in Appendix 1). An alignment of development sectors with these stressors provided a way of clarifying the many overlapping interactions with migratory birds (see Table A1.4 in Appendix 1). For example, "patch clearing" and "linear clearing" include the removal of surface vegetation in either a polygonal or linear pattern from forest harvesting, right-of-way development, and seismic lines. Major sources of these stressors include forest harvesting, oil sands development, conventional oil and gas, and the transportation network, with minor sources from mining, agriculture, and other forms of human use.

These stressors have direct and indirect impacts on habitats and/ or individuals, which ultimately affect migratory birds (middle portion of Fig. 3). Impacts on habitat include loss, 
Table 1. Core pathways of effect influencing migratory bird habitats as represented in Figure 3.

\begin{tabular}{|c|c|}
\hline Pathway of Effect & Description \\
\hline $\begin{array}{l}\text { (A) Stand-level habitat loss as a } \\
\text { result of industrial development }\end{array}$ & $\begin{array}{l}\text { Stand-level disturbances to forests as a result of urbanization, industrial development, and transportation } \\
\text { leading to habitat losses and potential decreases in regional populations. }\end{array}$ \\
\hline $\begin{array}{l}\text { (B) Landscape-level habitat loss as a } \\
\text { result of industrial development }\end{array}$ & $\begin{array}{l}\text { Landscape-level disturbances to forests as a result of urbanization, industrial development, and } \\
\text { transportation leading to losses and fragmentation of habitats and potential for negative influences on } \\
\text { regional populations. }\end{array}$ \\
\hline $\begin{array}{l}\text { (C) Stand-level impacts on habitat } \\
\text { quality }\end{array}$ & $\begin{array}{l}\text { A broad range of human activities leading to localized impacts on habitat quality that have the potential for } \\
\text { landscape-level and cumulative impacts on habitats and adverse effects on regional populations. }\end{array}$ \\
\hline $\begin{array}{l}\text { (D) Stand-level transformation as a } \\
\text { result of agriculture }\end{array}$ & $\begin{array}{l}\text { Stand-level transformations of forests as a result of agricultural conversion leading to potential losses/gains } \\
\text { and either negative or positive influences on regional populations, depending on habitat preferences. }\end{array}$ \\
\hline $\begin{array}{l}\text { (E) Landscape-level transformation } \\
\text { as a result of agriculture }\end{array}$ & $\begin{array}{l}\text { Landscape-level transformations of forests as a result of agricultural conversion leading to fragmentation } \\
\text { and losses/gains of habitats with either negative or positive influences on regional populations, depending on } \\
\text { habitat preferences. }\end{array}$ \\
\hline $\begin{array}{l}\text { (F) Stand-level transformation as a } \\
\text { result of forestry }\end{array}$ & $\begin{array}{l}\text { Stand-level transformations from older to young regenerating forest as a result of harvesting leading to } \\
\text { either negative or positive influences on regional populations, depending on habitat preferences. }\end{array}$ \\
\hline $\begin{array}{l}\text { (G) Landscape-level transformation } \\
\text { as a result of forestry }\end{array}$ & $\begin{array}{l}\text { Landscape-level transformations from older to young regenerating forest as a result of harvesting leading to } \\
\text { fragmentation and either negative or positive influences on regional populations, depending on habitat } \\
\text { preferences. }\end{array}$ \\
\hline $\begin{array}{l}\text { (H) Landscape-level transformation } \\
\text { as a result of changes in forest fire } \\
\text { dynamics }\end{array}$ & $\begin{array}{l}\text { Transformations of habitats from old to young regenerating forest as a result of changes in forest fire } \\
\text { dynamics, i.e., wildfire, human-caused fires, and fire suppression, leading to stand- and landscape-level } \\
\text { changes with potential negative or positive influences on regional populations, depending on habitat } \\
\text { preferences. }\end{array}$ \\
\hline
\end{tabular}

transformation, and degradation. Impacts on behavior and health include interference with a species' ability to conduct its normal activities, especially foraging and movement among habitats, or may cause stress, injury, disease, malnutrition, and toxicity. Impacts on survival include different sources of human-induced mortality, e.g., intentional and incidental take, and natural mortality, e.g., predation, senescence/loss of vigor, disease, and starvation, which can also be altered by human-induced changes in habitat. Impacts on nesting are influenced by the availability of habitat and processes that interfere with successful nesting. Underlying mechanisms of influence include predation or parasitism of nests, destruction of nests by human actions or severe weather, detrimental changes in habitat quality, or disturbance as a result of human intrusion.

Because of its breadth, the forest bird model lacked the specificity required to inform the model weighting process with experts. Using this generic model, we identified 8 distinct habitat pathways of effect (Table 1) and 11 related causal mechanisms (Table 2) affecting life-stage and population-level responses. The habitat pathways of effect were distinguished according to their spatial scale of effect, type of habitat impact, and form of habitat disturbance based on the sector of origin. The full set of habitat pathways is summarized in more detail in Table A1.5 of Appendix 1.

\section{Model weightings}

Results from a series of structured exercises with experts were used to derive weightings of importance of different components in the forest bird model to inform priorities for monitoring. On a linear scale between 0 and 1 , the weighting of 3 life stages indicated that experts, in aggregate, placed relatively more importance on pathways influencing breeding bird habitats $(0.44)$ compared with those affecting overwintering habitats $(0.35)$ and migratory life stages ( 0.21 ; see Fig. 4$)$. A fist-to-five vote revealed a somewhat divergent and moderate level of support for these results with an average support of 3.1 out of 5 and votes ranging from 1 to 5. The support of experts was related to how strongly the combined weightings aligned with an individual's original responses. This finding led to reanalysis of the data that revealed 2 contrasting opinions of experts, with group 1 weighting the breeding life stage as most important (0.63) and group 2 weighting overwintering habitats as most important $(0.57)$.

Fig. 4. Expert judgments on the relative importance of influences on different migratory bird life stages derived from a pairwise comparison exercise. Results are for all experts combined $(\mathrm{n}=8)$ and when separated into two groups (group 1, $\mathrm{n}=5$; group $2, \mathrm{n}=3$ ).

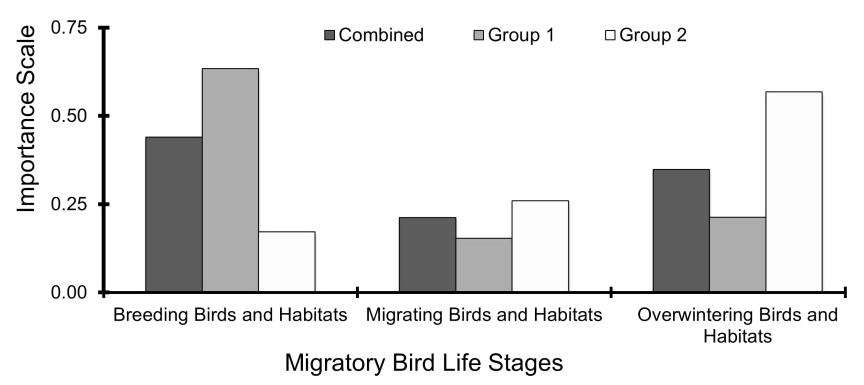

On a linear 5-point scale from not at all important to extremely important, 19 stressors were rated by experts based on their anticipated impact on the quality of breeding habitats in the study area (Fig. 5). The most important stressor, patch clearing, was consistently rated by experts as extremely important because of the potential for direct loss of nesting sites. The next important stressors, rated as more than somewhat important, included 
Table 2. Core causal mechanisms underlying the pathways of effect described in Table 1 and represented in Figure 3.

\begin{tabular}{ll}
\hline \hline Causal Mechanism & Description \\
\hline $\begin{array}{l}\text { (a) Displacement 1: } \\
\text { complete loss }\end{array}$ & $\begin{array}{l}\text { Physical changes to habitat rendering it completely unusable for a species, but without the additive effects } \\
\text { of other things below. Loss of all individuals of a species in a given area. }\end{array}$ \\
partial loss & $\begin{array}{l}\text { Physical changes to habitat rendering it usable for fewer individuals of a species, i.e., fewer appropriate nest } \\
\text { sites primarily. Loss of some to most individuals of a species in a given area. Other changes are considered } \\
\text { as separate mechanisms below. }\end{array}$ \\
(c) Dispersal & $\begin{array}{l}\text { Decreased connectivity of patches affecting movement of individuals. } \\
\text { Increased nest predation leading to mortality of eggs and nestlings. }\end{array}$ \\
eggs and nestlings & Increased predation of adults and mobile young. \\
(e) Predation 2: & $\begin{array}{l}\text { Increased nest parasitism. } \\
\text { adults and mobile young } \\
\text { (f) Parasitism }\end{array}$ \\
(g) Weather & $\begin{array}{l}\text { Nonlethal stress and direct mortality from extreme weather events that increase in intensity and frequency } \\
\text { as a result of climate change. }\end{array}$ \\
Changes to ecological conditions such as spring phenology and insect emergence timing as a result of \\
(h) Climate
\end{tabular}

Fig. 5. Expert judgments on the average relative importance of 19 stressors affecting quality of breeding habitats for migratory birds in the study area. Error bars represent $95 \%$ confidence intervals around each mean based on the variation in responses across experts.

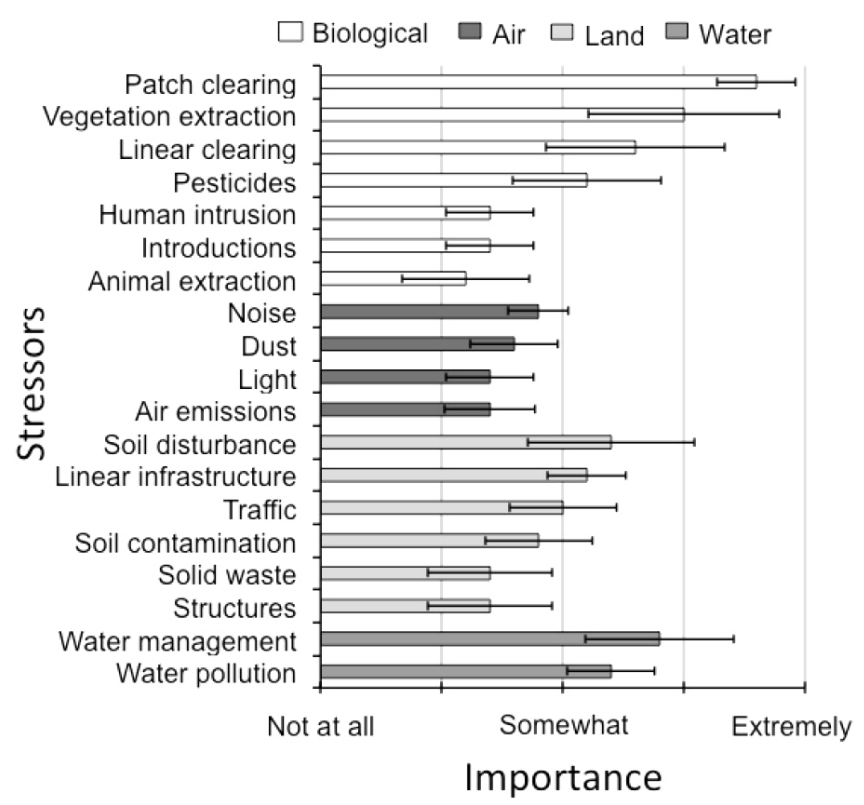

vegetation extraction, water management, and linear clearing because of their impact on availability of nesting sites; pesticides, soil disturbance, and water pollution because of their impact on foraging activities and food sources; and linear infrastructure and traffic because of their direct impact on survival. All other stressors were rated as less than somewhat important, specifically human intrusion, introductions, animal extraction, noise, dust, light, air emissions, soil contamination, solid waste, and structures. For several stressors, there was a wide variation in responses across experts, which included vegetation extraction, linear clearing, pesticides, soil disturbance, and water management. A vote revealed a relatively strong and consistent level of support for these rankings across experts, with an average of 3.6 out of 5 and votes ranging from 2 to 4 .

An MNL model was developed using data from the best-worst scaling exercise to estimate the importance of each pathway's influence on abundance and distribution of migratory birds in the study area. Parameter estimates in the model were rescaled to derive an interval scale of importance ranging from 1 (least important) to 8 (most important). A process of ranking was repeated on 3 occasions to encourage experts to share information and learn from each other. Variation (standard error) in responses across experts declined, and the relative ranking of pathways changed with each iteration of the exercise (Fig. 6). For the final iteration, habitat alterations as a result of agriculture and forestry were rated as having the strongest relative importance, with effects at the stand level (pathways D and F) being more important than the landscape level (pathways E and G). Pathways associated with industrial development (pathways A and B) were rated as slightly less important than top-rated pathways, but significantly higher than stand-level impacts on habitat quality (pathway C) and landscape-level transformations as a result of changing fire dynamics (pathway $\mathrm{H}$ ).

Despite minor variations, patterns in the relative strength of influence of different causal mechanisms were largely similar across the eight habitat pathways. Expert judgments on the most influential causal mechanisms underlying stand-level conversion 
Fig. 6. Scatter plot of the average relative importance of 8 habitat pathways of effect against the standard error around each rank based on the variation in responses across experts. Pathways are defined in Table 1. Interval scale of importance ranges from 1 (least important) to 8 (most important), derived by rescaling parameter values from a multinomial logit model to represent probability that a particular pathway would be selected as most important. Data are plotted for 3 iterations of ranking by experts using a maximum difference conjoint exercise. Arrows illustrate the change in importance and standard error for mechanism (a) across iterations. Iteration 3 represents the final ranking.

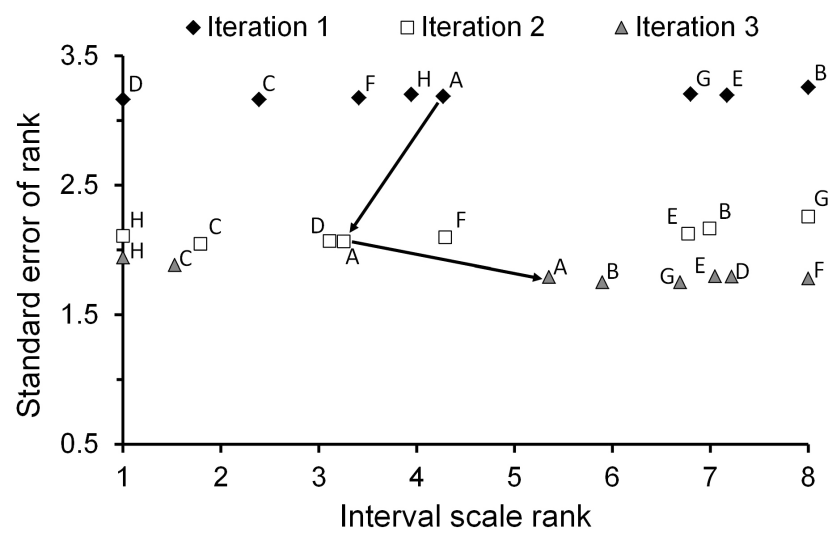

as a result of industrial development (pathway A) are shown in Figure 7. Habitat-mediated mechanisms leading to displacement and either complete (mechanism a) or partial (mechanism b) loss were consistently rated as having a major influence. A reduction in fecundity (mechanism $\mathrm{k}$ ) was seen as being moderately influential, whereas dispersal (mechanism c), food (mechanism i), direct mortality (mechanism $\mathrm{j}$ ), and predation at varying ages (mechanisms $\mathrm{d}$ and e) were rated as having less influence. Parasitism (mechanism f), weather (mechanism g), and climate (mechanism $\mathrm{h}$ ) were rated as having the weakest influence on this pathway.

\section{DISCUSSION}

\section{Representing complexity}

Developing visualizations to represent complexity of the study area was extremely challenging and time consuming. Although systems thinking encourages a more holistic representation of a system, the level of model completeness and complexity had to be balanced against the need for comprehension and simplicity to support clear communication. Technical experts demonstrate this dichotomy by advocating for simple conceptual models, yet simultaneously requiring that such models reflect observed complexities. More broadly, the realities of natural resource management also suggest that complex systems should be managed in a more holistic and integrated way but require simplification and prioritization to identify key variables that account for most changes (Mitchell et al. 2014). In our research, conceptual model development provided a clear framework for representing the ecosystem using a solid foundation of scientific
Fig. 7. Expert judgments on the strength of influence and certainty of evidence around the causal mechanisms underlying pathway of effect (A) and its influence on migratory birds in the study area. Mechanisms are listed in Table 2. Error bars represent $95 \%$ confidence intervals around each mean based on variation in responses across experts.

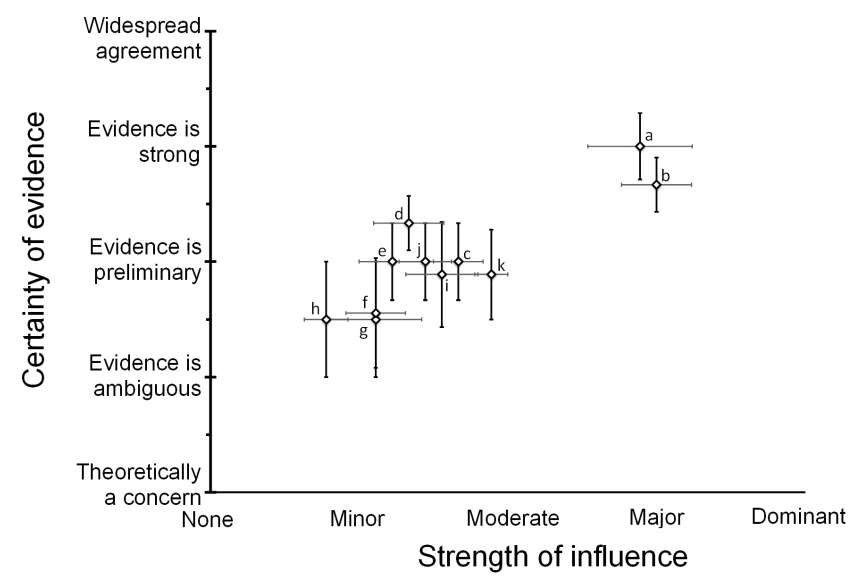

evidence and expert opinion. As highlighted by the tenet "simplicity often lies on the other side of complexity" (E. Berlow, TED Talk, http://www.ted.com/talks/eric berlow how complexity leads to simplicity?language $=$ en), the complexity of models evolved over these stages, initially increasing in complexity as the breadth and depth of models evolved and then decreasing as our understanding and artistry with which to represent the system improved (Fig. 2). No level of complexity was seen as best serving all audiences and purposes. Rather, multiple models with a range of complexities were developed to provide a strong foundation from which to structure the elicitation of expert judgments and to serve the communication needs of other audiences, meeting the primary purpose of using the models to inform the monitoring program design.

A hierarchy of conceptual models proved useful for characterizing the ecosystem because it forced a decrease in breadth and an increase in specificity at each level in the model and allowed for the use of different models at different scales. For instance, species-level models were the most detailed but also the easiest to develop because they were constrained in scope, grounded in the structure of the guild-level models, and supported with readily available summaries of evidence. The simultaneous development of our suite of models, from ecosystem level to species level, created several advantages. Internal coherence was the principle design advantage, especially the obvious linkages from the landscape- to the species-level models. This coherence helped enforce comprehensiveness and rigor across all models by ensuring a common typology and framework to accurately represent the many species, habitats, drivers, and stressors within the ecosystem.

The relatively detailed mechanistic structure of the models clarified the cumulative and interactive nature of factors influencing migratory birds both within and outside the study 
area. Within the study area, this approach emphasized how multiple industries produce the same types of stressors. As is required for most scientific investigations of cause and effect, these interactions emphasize the need to partition monitoring between affected and unaffected areas to attribute changes in population distribution and/or abundance to individual industries. However, the spatial extent of development, size of the study area, and the sometimes overlapping and sometimes spatially clustered land uses mean it will be difficult to find suitable reference areas to make regional population inferences. The approach also enabled a clear representation of carryover effects across life stages (Norris 2005) and the significant influence of factors outside of the oil sands area for one-half to three-quarters of the annual calendar for most migratory birds, including significant mortality during migration periods (Sillet and Holmes 2002). Although the mechanistic approach facilitated development of individual pathways of effect within the breeding season, which was needed to engage experts in the near term and inform priorities for the monitoring program in the longer term, a disadvantage is that few data are available to support partitioned modeling of the system in detail. Therefore, direct links with existing landscape simulation models incorporating birds are limited but are growing as an emerging property of the monitoring efforts achieved in the area (L. Mahon, personal communication).

\section{Integrating expert judgments}

Engagement of technical experts at selective points in our research facilitated and strengthened conceptual model development (Fig. 2). This approach was based on a view that the collective intelligence of many is superior to that of a few (Fisher and Fisher 1998). Compared with other audiences (Nelitz and Beardmore, in press), the perspectives of scientists required unique considerations given their strong level of technical understanding, the detail that is often required for them to provide meaningful input, and their sometimes poorly calibrated or self-serving opinions (Tversky and Kahneman 1974). These considerations affected our approach to engagement, the form of knowledge being elicited, and the way in which expert judgments were used. When combined with the conceptual models, these judgments were compatible with more traditional forms of scientific evidence. The participation of scientists helped improve and validate conceptual models in the early phases of development as expected from a traditional peer review. In the later stages, there was some initial reluctance among experts to use structured elicitation techniques to represent their judgments, in part because of some of the inherent challenges and biases that can be introduced into the results (Martin et al. 2012). Although efforts were made to address their concerns, experts tended to view the ecosystem in highly uncertain and in slightly different ways, meaning that it was not possible to frame the survey in a way that satisfied all perspectives. We were able to overcome one unanticipated challenge in the initial framing in which experts had difficulty disentangling the causal mechanisms from the pathways of effect that influence migratory birds. This difficulty led to adjustments in the design and iterative deployment of the MDC exercise. Despite these challenges, there were value-added benefits of formally integrating expert judgments because they provided additional information beyond the research and synthesis undertaken by the research team.
The use of structured survey exercises, i.e., pairwise comparisons, Likert scaling, and the MDC, provided significant advantages for integrating expert judgments. Foremost, we were able to tailor each task to the unique information inputs such that a quantitative weighting and measure of variance could be generated as an output. This approach allowed for the development of a common framework for discussing and analyzing the varied opinions of experts, each of whom brought different mental models and reference points to each task. For instance, despite similar access and knowledge of the available evidence, experts held divergent opinions about the importance of different life stages on population-level production of migratory birds in the study area (Fig. 4). A quantitative representation of this dichotomy was more potent than might have been revealed through less structured, i.e., dialogic, forms of engagement. A rating of stressors helped separate items into three bins of importance, although this was less informative for a finer level of discrimination given the variation in responses across experts (Fig. 5). An iterative MDC exercise was helpful in improving the level of agreement across the group and separating high-influence pathways as a result of forestry, agriculture, and industrial development from pathways leading to impacts on habitat quality and pathways related to natural processes such as wildfire (Fig. 6). Finally, a rating task to identify the strength of influence and certainty of evidence helped confirm the key mechanisms underlying many of the pathways of effect and illustrate a correlation in which mechanisms with more influence also tended to be rated as those with greater certainty of evidence (Fig. 7). Collectively, these exercises were helpful for quantifying the average opinion and variation in opinion across experts and providing measures of the relative weightings of importance of different influences on migratory birds.

In addition to the structured exercises, an innovative combination of supporting tools helped us effectively engage the group. A virtual meeting process, i.e., a conference call, online polling, desktop sharing, and a web-deployed survey, encouraged participation by limiting the travel required of a geographically distributed group of individuals from across North America. A financial incentive was also provided. Although its importance was largely seen as symbolic, and in some cases was not accepted, it helped individuals to prioritize this effort among the many other activities that impose constraints on their time. Enablers of participation were important given the level of specialization of experts required and the relatively limited number of individuals who could potentially contribute to this exercise. Such considerations are important when compared with public opinion surveys, in which the potential sample population is much larger. Deployment of the survey using a uniquely designed web platform provided us the capability of presenting an abundance of complex technical information and developing a common understanding of the study area with the group. This platform also provided us the flexibility to easily overcome an initial problem with the framing of one set of questions, leading to a reframing and rapid redeployment of the survey. The use of the Delphi method for one exercise harnessed the learning potential of the group and helped avoid individual biases by encouraging information sharing among experts and researchers. This approach led to less variation in responses across iterations of the exercise (Fig. 6). 
Finally, a consensus voting system was more informative than a simpler yes-no voting system because it facilitated expression of independent opinions and illuminated areas of agreement and disagreement across experts (Fig. 4). This combination of additional tools and techniques proved powerful for drawing on the collective intelligence of the group.

\section{CONCLUSION}

To date, this work has influenced the design and collection of hypothesis-driven research on cause-and-effect questions in the study area. Specifically, researchers have indicated that the models highlighted the importance of examining multisector and multistressor systems that overlap in space and time, articulating the nature of cumulative effects across sectors, rather than trying to isolate their investigations to oil and gas. Researchers have also focused on habitat disturbance on the breeding grounds because it was identified as a priority influence. The variation in expected responses highlighted that both species and community responses need to be investigated simultaneously. The models served an additional and important function of explaining to managers many aspects of the generic nature of disturbances from multiple industries, e.g., linear features, that cannot necessarily be compartmentalized as an "oil sands" effect versus other active industries. These conceptual models have been as much a communication tool as a touchstone to guide research.

The application of our research to the oil sands of northern Alberta, Canada, provides interesting insights that are relevant to other complex social-ecological settings. The study area features a naturally dynamic and biodiverse landscape overlaid with a high level of human development and economic intensity from a wide range of sectors, alongside contentious political and stakeholder oversight. Although there is a large quantity of specific information about the study area, there remains a relatively weak understanding about how the system functions, as highlighted by criticisms of past monitoring that was unable to detect significant effects (Dowdeswell et al. 2010, Kelly et al. 2010, Kvisle et al. 2011) and unresolved disputes around the impacts of oil sands on biodiversity in the region (Wasser et al. 2011, 2012, Boutin et al. 2012). Some combination of these factors has led to commitments by government to provide "a world class monitoring program for the oil sands to provide assurance of environmentally responsible development of the resource" with specific objectives to "support sound decision-making," "ensure transparency," and "enhance science-based monitoring," which are ideal aspirations for any effective monitoring program (GOC 2012:2).

Resource development in Canada and elsewhere is being more thoroughly scrutinized, requiring scientists to provide strong evidence and managers to make difficult decisions in increasingly complex settings where "facts are uncertain, values in dispute, stakes high, and decisions urgent" (Funtowicz and Ravetz 1992, as cited in Jones 2011:15). In such situations, there is an unavoidable need to address challenges of complexity and uncertainty. With this case study, addressing these challenges to inform priorities for monitoring required representing the complexity of the system to provide a more fulsome view of the breadth and depth of influences affecting migratory birds, as well as integrating expert judgments to help address the incomplete understanding about system behavior. In our view, this context enabled the use of conceptual modeling and expert elicitation as ways of improving transparency and increasing the diversity of input to support development of a more scientifically defensible monitoring program. The combination of these strategies was innovative and proved useful.

Responses to this article can be read online at: http://www.ecologyandsociety.org/issues/responses. $\mathrm{php} / 7906$

\section{Acknowledgments:}

Funding for this work was provided by Environment Canada. We extend our thanks for the considerable efforts of experts in their review and weighting of pathways in the conceptual models. Experts attending the review workshop included Caroline Bampfylde, Erin Bayne*, Craig Dockrill, Gillian Donald, Daniel Farr*, Meg Krawchuk, Lisa Mahon*, Hannah McKenzie, Sarah McLean, Hugh Norris, Rob Rempel*, Samantha Song*, Colleen Cassady St. Clair*, Lisa Venier, Richard Wiacek*, and Scott Wilson. Experts participating in the remote elicitation workshop included all of the above names with an asterisk as well as Steve Matsuoka, Wayne Thogmartin, and Steve Van Wilgenburg. Aaron Stephenson assisted in deployment of the expert survey. Katherine Kellock and Tyler Kydd helped with map and manuscript preparation.

\section{LITERATURE CITED}

Bech, M., and D. Gyrd-Hansen. 2005. Effects coding in discrete choice experiments. Health Economics 14(10):1079-1083. http:// dx.doi.org/10.1002/hec.984

Boutin, S., M. S. Boyce, M. Hebblewhite, D. Hervieux, K. H. Knopff, M. C. Latham, A. D. M. Latham, J. Nagy, D. Seip, and R. Serrouya. 2012. Why are caribou declining in the oil sands? Frontiers in Ecology and the Environment 10(2):65-67. http://dx. doi.org/10.1890/12.WB.005

Browman, H. I., and K. I. Stergiou, editors. 2004. Perspectives on ecosystem-based approaches to the management of marine resources. Marine Ecology Progress Series 274:269-303. http://dx. doi.org/10.3354/meps274269

Canter, L., and B. Ross. 2010. State of practice of cumulative effects assessment and management: the good, the bad and the ugly. Impact Assessment and Project Appraisal 28(4):261-268. http://dx.doi.org/10.3152/146155110x12838715793200

Cilliers, P., H. C. Biggs, S. Blignaut, A. G. Choles, J. S. Hofmeyr, G. P. W. Jewitt, and D. J. Roux. 2013. Complexity, modeling, and natural resource management. Ecology and Society 18(3): 1. http://dx.doi.org/10.5751/es-05382-180301

Cohen, S. H. 2003. Maximum difference scaling: improved measures of importance and preference for segmentation. Research Paper Series. Sawtooth Software Inc., Sequim, Washington, USA.

DiGennaro, B., D. Reed, C. Swanson, L. Hastings, Z. Hymanson, M. Healey, S. Siegel, S. Cantrell, and B. Herbold. 2012. Using conceptual models and decision-support tools to guide ecosystem 
restoration planning and adaptive management: an example from the Sacramento-San Joaquin Delta, California. San Francisco Estuary \& Watershed Science 10(3):1-15.

Donlan, C. J., D. K. Wingfield, L. B. Crowder, and C. Wilcox. 2010. Using expert opinion surveys to rank threats to endangered species: a case study with sea turtles. Conservation Biology 24 (6):1586-1595. http://dx.doi.org/10.1111/j.1523-1739.2010.01541. $\underline{\mathrm{X}}$

Dowdeswell, L., P. Dillon, S. Ghoshal, A. Miall, J. Rasmussen, and J. P. Smol. 2010. A foundation for the future: building an environmental monitoring system for the oil sands. Environment Canada, Ottawa, Ontario, Canada.

Duinker, P. N., and L. A. Greig. 2006. The impotence of cumulative effects assessment in Canada: ailments and ideas for redeployment. Environmental Management 37(2):153-161. http:// dx.doi.org/10.1007/s00267-004-0240-5

Environment Canada. 2011. Integrated monitoring plan for the oil sands, terrestrial biodiversity component. Government of Canada, Ottawa, Ontario, Canada.

Finn, A., and J. J. Louviere. 1992. Determining the appropriate response to evidence of public concern: the case of food safety. Journal of Public Policy \& Marketing 11:12-25.

Fischenich, J. C. 2008. The application of conceptual models to ecosystem restoration. Technical Note EMRRP-EBA-01. U.S. Army Engineer Research and Development Center, Vicksburg, Mississippi, USA.

Fisher, K., and M. D. Fisher. 1998. The distributed mind: achieving high performance through the collective intelligence of knowledge work teams. AMACOM, New York, New York, USA.

Flynn, T. N., J. J. Louviere, T. J. Peters, and J. Coast. 2007. Bestworst scaling: what it can do for health care research and how to do it. Journal of Health Economics 26:171-189. http://dx.doi. org/10.1016/j.jhealeco.2006.04.002

Gosselin, P., S. E. Hrudey, M. A. Naeth, A. Plourde, R. Therrien, G. Van Der Kraak, and Z. Xu. 2010. The Royal Society of Canada expert panel: environmental and health impacts of Canada's oil sands industry. Royal Society of Canada, Ottawa, Ontario, Canada.

Government of Canada (GOC). 2012. Joint Canada-Alberta implementation plan for oil sands monitoring. GOC, Ottawa, Ontario, Canada.

Grant, W. E., E. K. Pedersen, and S. L. Marin. 1997. Ecology and natural resource management: systems analysis and simulation. John Wiley and Sons, New York, New York, USA.

Gray, S., M. Paolisso, R. Jordan, and S. Gray, editors. In press. Environmental modeling with stakeholders. Springer International, Cham, Switzerland.

Hofer, E. 1986. On surveys of expert opinion. Nuclear Engineering and Design 93(2-3):153-160. http://dx.doi.org/10.1016/0029-5493 (86)90214-1

Jones, H. 2011. Taking responsibility for complexity: how implementation can achieve results in the face of complex problems. Working Paper 330. Overseas Development Institute, London, UK.
Kelly, E. N., D. W. Schindler, P. V. Hodson, J. W. Short, R. Radmanovich, and C. C. Nielsen. 2010. Oil sands development contributes elements toxic at low concentrations to the Athabasca River and its tributaries. Proceedings of the National Academy of Sciences of the United States of America 107:16178-16183. http:// dx.doi.org/10.1073/pnas.1008754107

Kvisle, H., J. Doucet, W. Kindierski, A. Miall, D. Pryce, J. Rasmussen, G. Taylor, H. Tennant, R. Wallace, H. Wheater, and D. Williams. 2011. A world class environmental monitoring, evaluation and reporting system for Alberta: the report of the Alberta Environmental Monitoring Panel. Alberta Environmental Monitoring Panel, Edmonton, Alberta, Canada.

Linstone, H. A., and M. Turoff, editors. 2002. The Delphi method: techniques and applications. Addison-Wesley, Reading, Massachusetts, USA.

Louviere, J. J., D. A. Hensher, and J. D. Swait. 2000. Stated choice methods: analysis and applications. Cambridge University Press, Cambridge, UK. http://dx.doi.org/10.1017/cbo9780511753831

Louviere, J. J., and G. Woodworth. 1983. Design and analysis of simulated consumer choice or allocation experiments: an approach based on aggregate data. Journal of Marketing Research 20:350-367. http://dx.doi.org/10.2307/3151440

Lynam, T., W. De Jong, D. Sheil, T. Kusumanto, and K. Evans. 2007. A review of tools for incorporating community knowledge, preferences, and values into decision making in natural resources management. Ecology and Society 12(1): 5. [online] URL: http:// www.ecologyandsociety.org/vol12/iss1/art5/

Marcot, B. G., R. S. Holthausen, M. G. Raphael, M. M. Rowland, and M. J. Wisdom. 2001. Using Bayesian belief networks to evaluate fish and wildlife population viability under land management alternatives from an environmental impact statement. Forest Ecology and Management 153:29-42. http://dx. doi.org/10.1016/S0378-1127(01)00452-2

Martin, T. G., M. A. Burgman, F. Fidler, P. M. Kuhnert, S. LowChoy, M. McBride, and K. Mengersen. 2012. Eliciting expert knowledge in conservation science. Conservation Biology 26 (1):29-38. http://dx.doi.org/10.1111/j.1523-1739.2011.01806.x

McDaniels, T., S. Wilmot, M. Healey, and S. Hinch. 2010. Vulnerability of Fraser River sockeye salmon to climate change: a life cycle perspective using expert judgements. Journal of Environmental Management 91:2771-2780. http://dx.doi.org/10.1016/ j.jenvman.2010.08.004

McFadden, D. 1974. Conditional logit analysis of qualitative choice behaviour. Pages 105-142 in P. Zarembka, editor. Frontiers in econometrics. Academic Press, New York, New York, USA.

Meadows, D. H. 2008. Thinking in systems: a primer. Chelsea Green, White River Junction, Vermont, USA.

Mitchell, B., K. Bellette, and S. Richardson. 2014. 'Integrated' approaches to water and natural resources management in South Australia. International Journal of Water Resources Development, in press. http://dx.doi.org/10.1080/07900627.2014.979399

Morgan, M. G., and M. Henrion. 1990. Uncertainty: a guide to dealing with uncertainty in quantitative risk and policy analysis. Cambridge University Press, New York, New York, USA. http:// dx.doi.org/10.1017/cbo9780511840609 
Nelitz, M. A., and B. Beardmore. In press. Eliciting judgments, priorities, and values using structured survey methods. In S. Gray, M. Paolisso, R. Jordan, and S. Gray, editors. Environmental modeling with stakeholders. Springer International, Cham, Switzerland.

Noon, B. R. 2002. Conceptual issues in monitoring ecological resources. Pages 27-72 in D. E. Busch and J. C. Trexler, editors. Monitoring ecosystems: interdisciplinary approaches for evaluating ecoregional initiatives. Island, Washington, D.C., USA.

Norris, D. R. 2005. Carry-over effects and habitat quality in migratory populations. Oikos 109:178-186. http://dx.doi. org/10.1111/j.0030-1299.2005.13671.x

Papageorgiou, E., and A. Kontogianni. 2012. Using fuzzy cognitive mapping in environmental decision making and management: a methodological primer and an application. Pages 427-450 in S. S. Young and S. E. Silvern, editors. International perspectives on global environmental change. InTech, Rijeka, Croatia. http://dx.doi.org/10.5772/29375

Pavlikakis, G. E., and V. A. Tsihrintzis. 2003. A quantitative method for accounting human opinion, preferences and perceptions in ecosystem management. Journal of Environmental Management 68(2):193-205. http://dx.doi.org/10.1016/s0301-4797 (03)00067-7

Raktoe, B. L., A. Hedayat, and W. T. Federer. 1981. Factorial designs. Wiley, New York, New York, USA.

Rastetter, E. B., J. D. Aber, D. P. C. Peters, D. S. Ojima, and I. C. Burke. 2003. Using mechanistic models to scale ecological processes across space and time. BioScience 53(1):68-76. http:// dx.doi.org/10.1641/0006-3568(2003)053[0068:ummtse]2.0.co;2

Salafsky, N., D. Salzer, A. J. Stattersfield, C. Hilton-Taylor, R. Neugarten, S. H. M. Butchart, B. Collen, N. Cox, L. L. Master, S. O'Connor, and D. Wilkie. 2008. A standard lexicon for biodiversity conservation: unified classifications of threats and actions. Conservation Biology 22(4):897-911. http://dx.doi. org/10.1111/j.1523-1739.2008.00937.X

Shochat, E., P. S. Warren, S. H. Faeth, N. E. McIntyre, and D. Hope. 2006. From patterns to emerging processes in mechanistic urban ecology. Trends in Ecology \& Evolution 21(4):186-191. http://dx.doi.org/10.1016/i.tree.2005.11.019

Sillett, T. S., and R. T. Holmes. 2002. Variation in survivorship of a migratory songbird throughout its annual cycle. Journal of Animal Ecology 71:296-308. http://dx.doi.org/10.1046/ j.1365-2656.2002.00599.x

Staudt, A., A. K. Leidner, J. Howard, K. A. Brauman, J. S. Dukes, L. J. Hansen, C. Paukert, J. Sabo, and L. A. Solórzano. 2013. The added complications of climate change: understanding and managing biodiversity and ecosystems. Frontiers in Ecology and the Environment 11(9):494-501. http://dx.doi.org/10.1890/120275

Suter, G. W., II, L. W. Barnthouse, and R. V. O’Neill. 1987. Treatment of risk in environmental impact assessment. Environmental Management 11(3):295-303. http://dx.doi.org/10.1007/ bf01867157

Teck, S. J., B. S. Halpern, C. V. Kappel, F. Micheli, K. A. Selkoe, C. M. Crain, R. Martone, C. Shearer, J. Arvai, B. Fischhoff, G.
Murray, R. Neslo, and R. Cooke. 2010. Using expert judgment to estimate marine ecosystem vulnerability in the California Current. Ecological Applications 20(5):1402-1416. http://dx.doi. org/10.1890/09-1173.1

Tversky, A., and D. Kahneman. 1974. Judgment under uncertainty: heuristics and biases. Science 185(4157):1124-1131. http://dx.doi.org/10.1126/science.185.4157.1124

Waltner-Toews, D., J. J. Kay, and N.-M. E. Lister, editors. 2008. The ecosystem approach: complexity, uncertainty, and managing for sustainability. Columbia University Press, New York, New York, USA.

Wasser, S. K., J. L. Keim, M. L. Taper, and S. R. Lele. 2011. The influences of wolf predation, habitat loss, and human activity on caribou and moose in the Alberta oil sands. Frontiers in Ecology and the Environment 9:546-551. http://dx.doi.org/10.1890/100071

Wasser, S. K., J. L. Keim, M. L. Taper, and S. R. Lele. 2012. To kill or not to kill - that is the question. Frontiers in Ecology and the Environment 10:67-68. http://dx.doi.org/10.1890/12.wb.006

Wittmann, M. E., R. M. Cooke, J. D. Rothlisberger, E. S. Rutherford, H. Zhang, D. M. Mason, and D. M. Lodge. 2015. Use of structured expert judgment to forecast invasions by bighead and silver carp in Lake Erie. Conservation Biology 29 (1):187-197. http://dx.doi.org/10.1111/cobi.12369 
Appendix 1. Summary of conceptual models for the boreal forest ecosystem of northern Alberta Canada Additional material for individual species is available from the authors by request or through Research Gate: https://www.researchgate.net/publication/281112203 Conceptual models of migratory birds and human de velopment as relevant to the oil_sands of_Canada 


\section{BACKGROUND}

The study area contains conventional oil and gas deposits, commercial forestry, agriculture, urbanization, a transportation network to support those industries and other, smaller economic interests (see Fig. 1 in the main manuscript, Table A1.1). These activities are in addition to the large scale influence of an active fire regime, insect disturbance and climate change. There is a long history of research and monitoring of birds in the oil sands area, including substantial work from 1975-1985 (under the Alberta Oilsands Environmental Research Program) and more recent monitoring work by companies under the Ecological Monitoring Committee for the Lower Athabasca, as well as agencies such as Alberta Biodiversity Monitoring Institute (ABMI) and the Alberta government. However, development of conceptual models for birds appears to have been limited to simple models used for recent environmental assessments (e.g., section 7.4 in Shell Canada Limited 2007). Models for remediation (Frid and Daniel 2012; Ciborowski and others 2013), as well as for other (non-bird) disciplines (Government of Alberta 2013) have also been created.

Table A1.1. Summary statistics for footprints originating from a variety of types of human disturbance across all sectors in the oil sands area of northern Alberta. Footprint data from ABMI (2010). The significant proportion of all disturbance by agriculture and forestry is highlighted in bold.

\begin{tabular}{lrrrr}
\hline Type of disturbance & $\begin{array}{c}\text { Total length of } \\
\text { disturbance } \\
(\mathrm{km})\end{array}$ & $\begin{array}{c}\text { Total area of } \\
\text { disturbance } \\
\left(\mathrm{km}^{2}\right)\end{array}$ & $\begin{array}{c}\text { Percent of all } \\
\text { disturbance }\end{array}$ & $\begin{array}{c}\text { Percent of } \\
\text { total area }\end{array}$ \\
\hline Borrow-pits / dugouts / sumps & $\begin{array}{r}1,839 \\
\text { Canals }\end{array}$ & 27.0 & 0.14 & 0.02 \\
Cultivation (crop, pasture, bare ground) & $\mathbf{8 2 , 3 0 1}$ & $\mathbf{1 0 , 4 8 9 . 9}$ & 0.00 & 0.00 \\
Cut blocks & $\mathbf{8 9 , 1 8 0}$ & $\mathbf{4 , 1 7 5 . 0}$ & $\mathbf{2 1 . 6 4}$ & $\mathbf{2 . 3 2}$ \\
High density livestock operation & 23 & 1.1 & 0.01 & 0.00 \\
Industrial site rural & 1,209 & 75.9 & 0.39 & 0.05 \\
Mine site & 7,387 & 726.6 & 3.77 & 0.44 \\
Municipal (water and sewage) & 112 & 8.5 & 0.04 & 0.01 \\
Other disturbed vegetation & 579 & 22.9 & 0.12 & 0.01 \\
Peat mine & 89 & 10.7 & 0.06 & 0.01 \\
Pipeline & 51,077 & 528.2 & 2.74 & 0.32 \\
Rail with hard surface & 1,807 & 8.3 & 0.04 & 0.01 \\
Rail with vegetated verge & 3,094 & 10.6 & 0.06 & 0.01 \\
Reservoirs & 175 & 17.3 & 0.09 & 0.01 \\
Road with hard surface & 42,432 & 239.0 & 1.24 & 0.14 \\
Road with vegetated verge & 84,036 & 392.4 & 2.03 & 0.24 \\
Road / trail (vegetated) & 32,096 & 177.8 & 0.92 & 0.11 \\
Rural (residential / industrial) & 11,053 & 355.7 & 1.84 & 0.21 \\
Seismic line & 498,767 & $1,237.6$ & 6.41 & 0.75 \\
Transmission line & 5,513 & 83.1 & 0.43 & 0.05 \\
Urban & 1,461 & 44.1 & 0.23 & 0.03 \\
Well site & 30,975 & 662.2 & 3.43 & 0.40 \\
\hline Totals & $\mathbf{9 4 5 , 2 7 4}$ & $\mathbf{1 9 , 2 9 4 . 2}$ & $\mathbf{1 0 0 . 0 0}$ & $\mathbf{1 1 . 6 3}$
\end{tabular}




\section{METHODS}

We began with a literature review to identify key features and types of conceptual models that would suit our needs (e.g., Jorgensen 1988; Fischenich 2008). We then selected model types that would best serve the varying target audiences, systems and processes of interest, levels of specificity, and information availability. We developed conceptual models at a hierarchy of scales - ecosystem, landscape, guild and species - given the ecological complexity of the study area and breadth of monitoring needs. There was an intentional decrease in breadth and increase in specificity in these models moving from the highest to lowest levels in the hierarchy. A systems model was used for the ecosystem level to illustrate the breadth of human stressors and natural drivers that influence the ecology of the study area. A state and transition model was used for the landscape level to represent habitat states and transitional processes that influence habitat dynamics, while a life cycle model was used to represent population dynamics for the migratory and resident terrestrial species occupying the study area. Life cycle models were also used for the guild level (and species level) to represent interactions between the environment and all forest and wetland dependent birds (or individual species) that migrate annually from or through the study area. Pathways-of-effect were prioritized using these guild-level models.

Five steps were followed to develop the conceptual models (adapted from Grant and others 1997; Fischenich 2008) on top of the technical guidance provided by Noon (2002). First, model objectives were stated according to intended uses and audiences. The ecosystem-level model was made for informed decision makers to provide them with a high-level understanding of the inter-relationships among all components of the terrestrial environment and diverse monitoring needs. The landscape-level models were developed to provide ecologists with an overview of the natural drivers and human stressors that influence species and habitats and to provide a consistent framework from which to develop more detailed guild- and species-level models. The guild-level model was targeted towards avian ecologists to represent the key natural and human processes that influence all migratory bird species and to serve as a template for developing species-level models. It was also developed to help prioritize monitoring needs and inform the avian monitoring design. Species-level models were intended to help avian ecologists develop investigations of causes of change in status or trend of the species.

Second, models were bounded according to subsystems of interest and related spatial / temporal boundaries. The focus (breadth) and level of specificity (depth) for each model were first clarified. This included understanding the development sectors, human activities, stressors, natural drivers, and valued ecosystem components (i.e., species and habitats) that were being represented. Each model's focus and specificity was driven in part by the model's purpose and intended audience, recognizing that more technical audiences require a greater level of specificity and complexity. The geographic extent was constrained to the oil sands area of 
northern Alberta and temporal horizon constrained to generations (i.e., decades). The annual life cycle of terrestrial biota (e.g., migratory forest birds) was also an important temporal frame for structuring the conceptual models.

Third, model components were identified. We assembled a range of evidence to identify the drivers, outcomes, and linkages to be represented in the conceptual models using summary or review literature relevant to the model scales. This evidence included information that was both specific and non-specific to the study area and was supplemented with the authors' experience and knowledge about ecosystem interactions. Drivers included natural influences and human stressors that affect the behaviour or state of the ecosystems' components. Outcomes included the direct and indirect results, impacts, or consequences of particular drivers. Linkages represented the connections between drivers and outcomes, such that each linkage was associated with an "effect" and a series of linkages from an initial driver to a final outcome was considered a "pathway-of-effects". Substantial effort was required to determine the appropriate level of specificity and language for describing human stressors and outcomes. The number of modeled stressors and outcomes needed to be manageable so they could be feasibly represented across levels of the hierarchy and be broadly relevant across many diverse development sectors and valued ecosystem components. For instance, we used the term "biomass extraction" to represent many forms of extraction as opposed to representing each specific activity separately (e.g., forest harvesting, agricultural harvesting, peat harvesting, and hunting).

The fourth step was to build the conceptual models to illustrate relationships among the drivers, outcomes, and linkages at each level in the hierarchy. All models were mechanistic in nature to illustrate the sequence of causal linkages or pathway-of-effects between a driver and an outcome of interest, even though field observations may not have been available to describe each step in the cause-effect chain. Models were also developed with the intention of being both independent of and interdependent with others (i.e., higher level models inform lower levels models). Models had to balance the requirement to represent all development sectors, stressors, habitats, and species for a large spatial area with the many interconnected and overlapping relationships among the stressors and biological outcomes at each level.

Lastly, models were qualitatively evaluated for consistency and robustness. Alternative scenarios of human development and ecosystem interactions were considered to test if the drivers, outcomes, and linkages were representative of and robust to the imagined range of driving conditions. Gaps were found in all cases because models did not sufficiently address the breadth or depth of interactions that were necessary at a particular level 
in the hierarchy. These gaps were ultimately addressed through multiple iterations of the models and accompanying narratives.

\section{MODEL DESCRIPTIONS}

Fourteen conceptual models were developed: one ecosystem, two landscape, two bird guild, and nine species models. To illustrate results across a range of hierarchies and landscape types (e.g., upland forests and wetlands), six models are described in text below. The remaining models are presented as figures and detailed descriptions or supporting text is available by contacting the authors or through Research Gate (https://www.researchgate.net/publication/281112203_Conceptual_models_of_migratory_birds_and_human_de velopment as relevant to the oil_sands_of_Canada)

\section{Ecosystem model}

The ecosystem model represents the entire extent of the study area which is within the Boreal Forest Natural Region of northern Alberta (Natural Regions Committee 2006, i.e. the area encompassed by Fig. 1 in the main manuscript). Model development was based on ecological information pertaining to the study area (Natural Regions Committee 2006; Demarchi 2010; PEG 2011), an understanding of regionally relevant human actions (ASRD 2002; CEMA 2008; Environment Canada 2011; Government of Alberta 2011) and an international system for classifying human threats (Salafsky and others 2008). Fig. A1.1 is the simplified model while Fig. A1.2 provides a more comprehensive representation of the ecosystem.

The model is built around abiotic (air, land, and water) and biotic (all habitats and species) components with dashed boundaries representing interactions among them (e.g., atmospheric influences on land and water, riparian interface between land and water, reliance of species and habitats on land, water, and air). Physical boundaries and important characteristics are included as ways of characterizing abiotic components. A looping arrow represents the dynamic

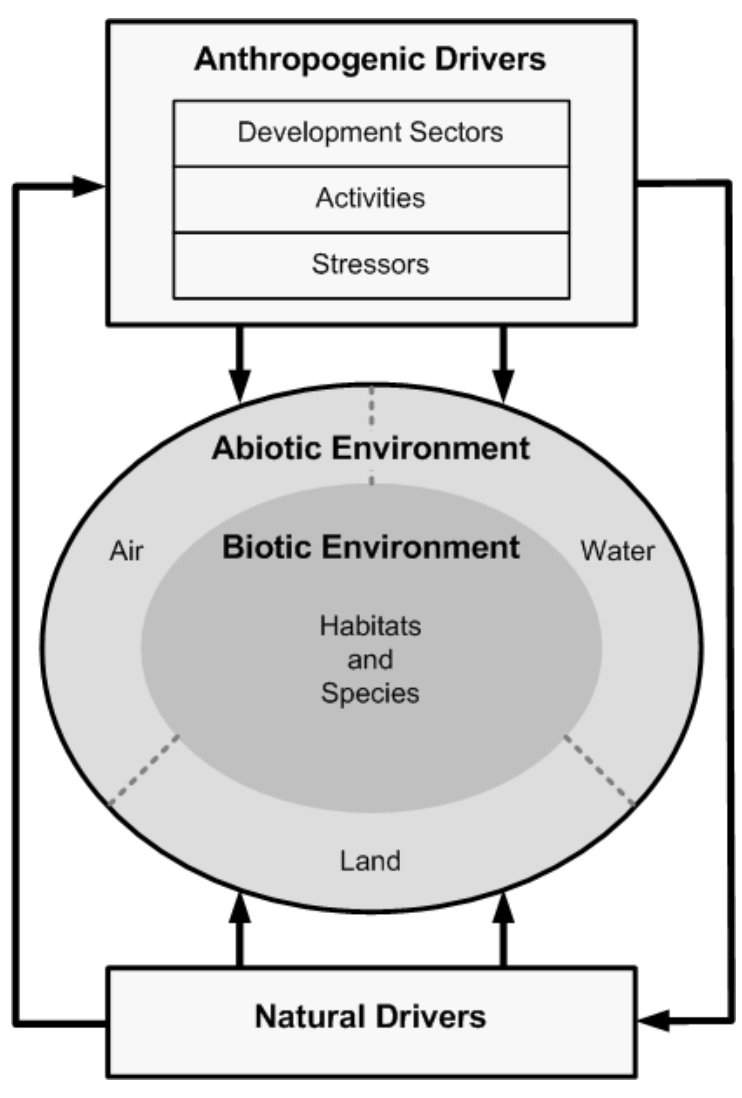

Fig. A1.1. Simplified ecosystem model for the study area. relationship between habitats and species. As well, changes in habitat conditions affect the composition of 
species that can be supported in a particular habitat. A broad (though not exhaustive) set of outcomes are listed which can include the pattern, composition, and processes used to describe habitats. Pattern-based outcomes are intended to include measures of the spatial configuration of habitats, such as patch-size distribution, area by habitat type, amount of forest edge, amount of interior forest area, and contiguousness. Composition-based outcomes include biodiversity, age-class distribution, availability of food resources, and existence of habitat structures. Process-based outcomes represent the connectivity of the landscape, barriers to movement, predatorprey dynamics, trophic interactions, fuel loads, carbon sequestration, and water retention, among others. Species outcomes are grouped according to different scales of biological organization - individual, population, species, and community levels. Each level represents complementary information about a species, including growth, survival and reproduction for individuals, abundance, trend, distribution, demographics, and capacity for populations, as well as species composition, species diversity and intactness at the community level.

The abiotic and biotic components are influenced by natural and anthropogenic drivers from within the study area. External influences from outside the study area are not explicitly represented, though they will occur (e.g., long-range transport of contaminants, pollution of downstream habitats). Natural drivers are grouped into five categories of processes: weather and climate, energy flow and nutrient cycling, natural disturbances, geomorphology, and hydrologic. Anthropogenic drivers are first represented by the range of development sectors occurring

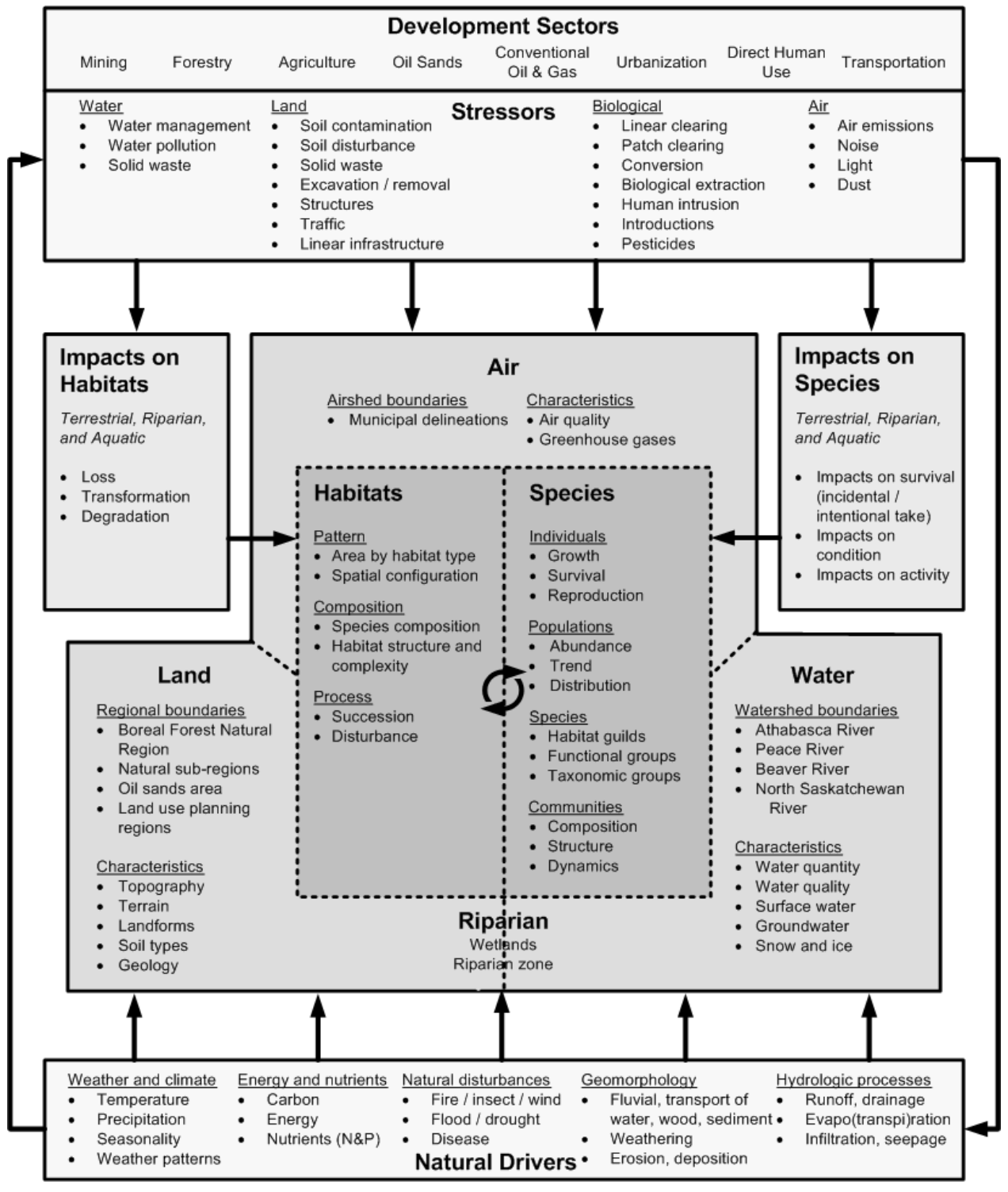

Fig. A1.2. The detailed ecosystem model representing biotic and abiotic components, as well as linkages to human stressors (top boxes) and natural drivers (bottom box) across the study area. 
on the landscape. Although not explicitly represented, many activities (e.g., road building, mining, forest harvesting) can be associated with these sectors. Each activity can be further associated with a generalized set of stressors (e.g., linear clearing, excavation, biomass extraction), such that the relationship between sectors and stressors is many-to-many. This list of stressors is not exhaustive; rather it is intended to capture the breadth of potential stresses to which the ecosystem is exposed. Stressors are grouped based on the dominant pathway by which their effect is mediated (e.g., water, land, air, biological). These groupings are fuzzy categorizations since certain stressors may affect multiple components of the environment under different conditions. As indicated by arrows, stressors can directly affect the natural drivers and abiotic components of the system, as well as lead to direct impacts on habitats (loss, transformation, or degradation) and species (lethal or sub-lethal effects).

\section{Landscape models}

The two sub-models for the landscape-scale are in Figs. A1.3 and A1.4. In addition to the citations used to develop the ecosystem model, this model relied upon established classification systems to define habitat types (ABMI 2009a), wetlands (Halsey and others 2004) and human footprints (ABMI 2010) for the study area.

The habitat dynamics sub-model (Fig. A1.3) represents the upland / forested and lowland / wetland habitat states (boxes) as well as the natural and human processes driving transitions among them (arrows). Upland areas (upper portion of model) consist of different types of forest and shrubland habitats, while lowland areas (lower portion of model) consist of different types of wetland habitats. The middle portion represents anthropogenic habitats, originating from transitions from both upland and lowland habitats (habitat states are described in Table A1.2). Major transitions among states affect the quantity of these habitats on the landscape (quality is not represented), which can result from both natural drivers (dashed lines) and human stressors (solid lines). Only a subset of the important drivers identified in the ecosystem model are relevant since only a portion affect quantity of terrestrial habitats leading to the exclusion of lower intensity influences (e.g., low severity ground fires) and stressors on habitat quality from this model.

The population dynamics sub-model (Fig. A1.4) illustrates how a population may interact with other species (i.e., competitors, predator, or prey), as well as how it is influenced by changes in the quantity and quality of habitats across the landscape. It is intended to represent the majority of terrestrial species occupying the study area. From right to left the model illustrates pathways-of-effects leading from natural drivers / human stressors to changes in habitat characteristics (habitat loss, transformation, or degradation) and species responses (change in mortality, activity, or condition) to proximate impacts on populations (births, deaths, immigration, and emigration) to population level effects (distribution, trend, and abundance). 


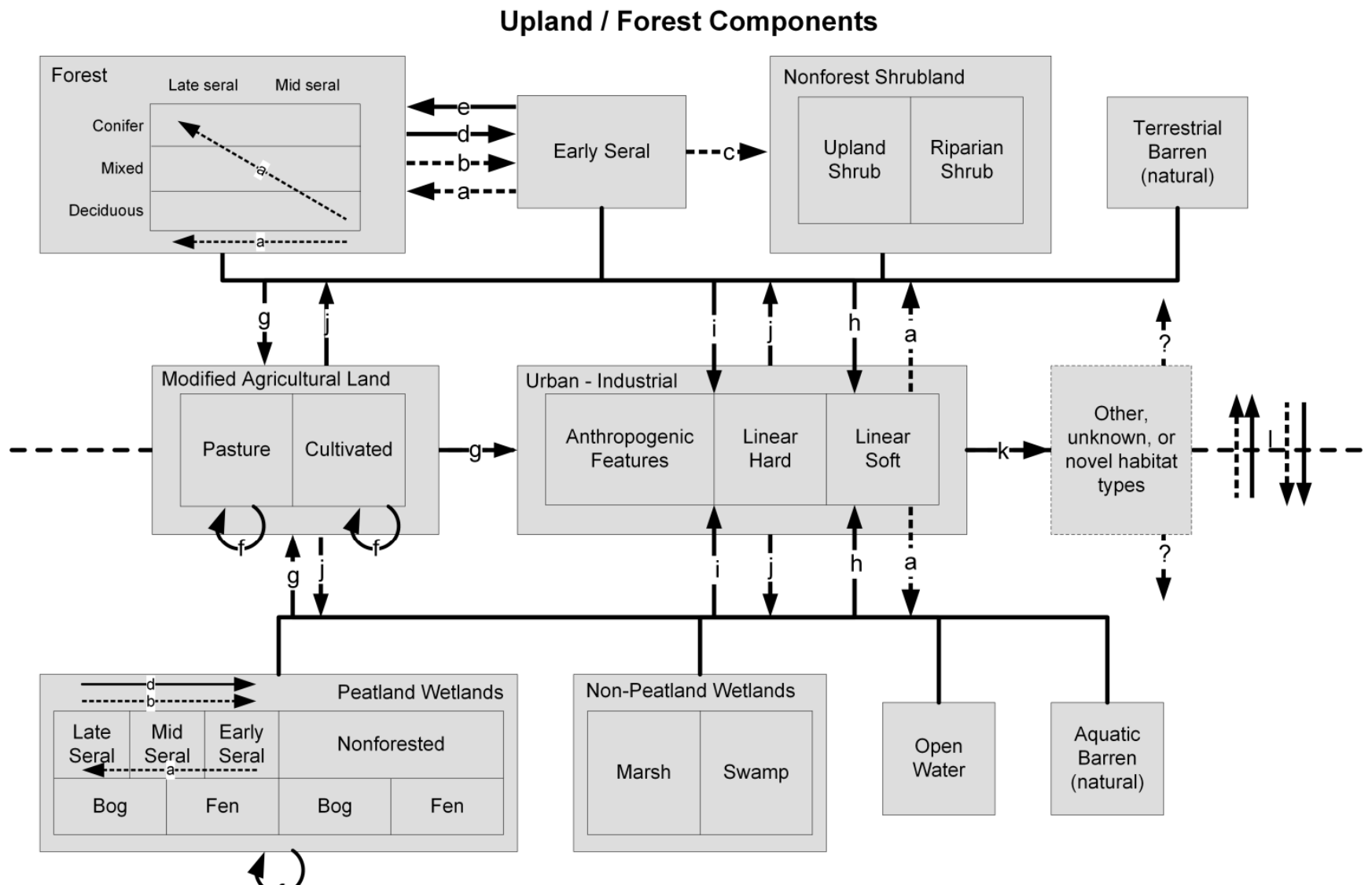

\section{Lowland / Wetland Components}

\section{Legend \\ a Natural succession (forest) \\ b Natural disturbance \\ c Natural succession (non-forest)}

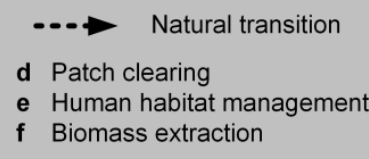

d Patch clearing

e Human habitat management

f Biomass extraction

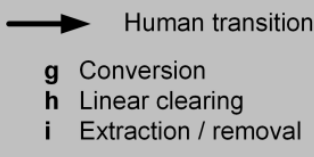

j Restoration / reclamation

k Oil sands mine site reclamation

I Upland-wetland transitions

Fig. A1.3. The landscape conceptual model, presented as a state-transition model, showing the dynamics of upland/forested and lowland/wetland states (boxes) as influenced by processes transforming habitats (arrows).

The left portion of the model represents the life cycle and movement of populations relative to three regions: the study area, landscapes adjacent to the study area, as well as migration and overwintering habitats of migrant species. The study area contains the annual cycle of generic resident species and a portion of the life cycle of a generic migrating species (e.g., during the breeding season and to/from overwintering habitats). The model is based on four processes affecting regional population status (births, deaths, immigration, and emigration). Human stressors and natural drivers are represented as simultaneously occurring in other regions. Population outcomes are represented at the centre of the lifecycle.

The middle portion of the model illustrates the pathways-of-effects that connect stressors/drivers on the right to four proximate processes on the left. Pathways-of-effect are grouped into seven generalized classes of impacts (shaded boxes). The dark shaded boxes represent habitat impacts that lead to changes in habitat quantity (loss 
Table A1.2. Description of habitat groupings and habitat states used in the landscape model (Fig. A1.3) and their relationship to landscape elements from the Alberta Biodiversity Monitoring Institute (ABMI 2009a).

\begin{tabular}{|c|c|c|}
\hline $\begin{array}{l}\text { Habitat } \\
\text { Groupings }\end{array}$ & Habitat States & Description of Landscape Elements (from AMBI) \\
\hline \multirow[t]{3}{*}{$\begin{array}{l}\text { Urban - } \\
\text { Industrial }\end{array}$} & $\begin{array}{l}\text { Anthropogenic } \\
\text { Features }\end{array}$ & $\begin{array}{l}\text { Anthropogenic Features: Any residential, industrial, including bare ground (does } \\
\text { not include agricultural crops / pasture and forestry cutting that are not linear) }\end{array}$ \\
\hline & Linear Hard & $\begin{array}{l}\text { Linear Hard: Linear corridor hard surface / nonvegetated (with material added to } \\
\text { increase access) }\end{array}$ \\
\hline & Linear Soft & Linear Soft: Linear corridor soft surface / vegetated \\
\hline $\begin{array}{l}\text { Modified } \\
\text { Agriculture }\end{array}$ & Cultivated & $\begin{array}{l}\text { Cultivated: Annual cereal crops, irrigated land, and bare soil, though excluding } \\
\text { forage and pasture }\end{array}$ \\
\hline Land & Pasture & $\begin{array}{l}\text { Pasture: Annual forage and pasture, including pasture in shrubland with evidence } \\
\text { of cultivation and pasture in recently cleared land }\end{array}$ \\
\hline \multirow[t]{4}{*}{ Forest $^{\mathrm{a}}$} & Conifer & Coniferous Dominated Forest: $>80 \%$ coniferous cover based on occurrence \\
\hline & Deciduous & Deciduous Dominated Forest: $>80 \%$ deciduous cover based on occurrence \\
\hline & Mixed & Mixed Wood Dominated Forest: $20-80 \%$ mixed wood cover based on occurrence \\
\hline & $\begin{array}{l}\text { Mid-Seral and } \\
\text { Late-Seral }\end{array}$ & $\begin{array}{l}\text { Coniferous, Deciduous and Mixed Wood Forests: Distinguished based on age } \\
\text { class of forest } 11-30,31-55,56-80,>80 \text { years }\end{array}$ \\
\hline $\mathrm{n} / \mathrm{a}$ & Early Seral $^{b}$ & $\begin{array}{l}\text { Early Seral: Combines several major landscape types: Natural Disturbed Forests in } \\
\text { Very Early Stages of Succession, Nonforest Grassland, Upland Nonforest Forbs, } \\
\text { Upland Nonforest Forbs, Human Modified Forest Land, and Forested Land with } \\
\text { Human Disturbance Not Visible Throughout the Stand }\end{array}$ \\
\hline NonForest & Upland Shrub & Closed / Open Upland Shrub: $>25 \%$ shrub cover and $<6 \%$ tree cover upland shrub \\
\hline Shrubland ${ }^{\mathrm{c}}$ & Riparian Shrub & $\begin{array}{l}\text { Closed / Open Riparian Shrub: }>25 \% \text { shrub cover and }<6 \% \text { tree cover riparian } \\
\text { shrub }\end{array}$ \\
\hline $\mathrm{n} / \mathrm{a}$ & Open Water ${ }^{\mathrm{d}}$ & Standing and Flowing Open Water: Lakes, ponds, reservoirs, rivers and streams \\
\hline $\mathrm{n} / \mathrm{a}$ & $\begin{array}{l}\text { Terrestrial Barren } \\
\text { (natural) }\end{array}$ & $\begin{array}{l}\text { Barren Terrestrial: Includes rock, talus, alluvial deposit, badland, blowout zone, } \\
\text { and upland dune field, }<6 \% \text { vegetation cover }\end{array}$ \\
\hline $\mathrm{n} / \mathrm{a}$ & $\begin{array}{l}\text { Aquatic Barren } \\
\text { (natural) }\end{array}$ & Barren Aquatic: Includes alkali flat, mud flat, and beaches \\
\hline \multirow[t]{5}{*}{$\begin{array}{l}\text { Peatland } \\
\text { Wetlands }\end{array}$} & $\begin{array}{l}\text { Early, Mid, and } \\
\text { Late Seral Forest }\end{array}$ & $\begin{array}{l}\text { No ABMI equivalent, though represents succession of forested wetlands } \\
\text { analogous to upland forests }\end{array}$ \\
\hline & Bog - Forested & Bog - Treed: Peatlands with $>6$ crown closure \\
\hline & Fen - Forested & Fen: Woodland fen \\
\hline & $\begin{array}{l}\text { Bog - } \\
\text { Nonforested }\end{array}$ & Bog - Open: Peatlands with $<6$ crown closure \\
\hline & $\begin{array}{l}\text { Fen - } \\
\text { Nonforested }\end{array}$ & $\begin{array}{l}\text { No ABMI equivalent, though consistent with Alberta Wetland Inventory } \\
\text { Classification System (Halsey and others 2004) }\end{array}$ \\
\hline Non-Peatland & Marsh & Marsh: Wetlands dominated by emergent vegetation (cattails) \\
\hline Wetlands & Swamp & Swamp: Graminoid Wetlands (sedges/grasses/forbs) \\
\hline
\end{tabular}

Footnotes:

${ }^{a}$ Landscape model reflects a more generalized classification of habitat states and forest age classes than ABMI. For instance, it does not differentiate among stand types based on canopy closure and/or species composition.

${ }^{\mathrm{b}}$ Landscape model does not differentiate among early seral stages of grassland, forbland, bryophyte, shrubland and forest.

${ }^{\mathrm{c}}$ Landscape model does not differentiate between closed and open shrublands.

${ }^{\mathrm{d}}$ Landscape model does not differentiate between standing and flowing open water. 


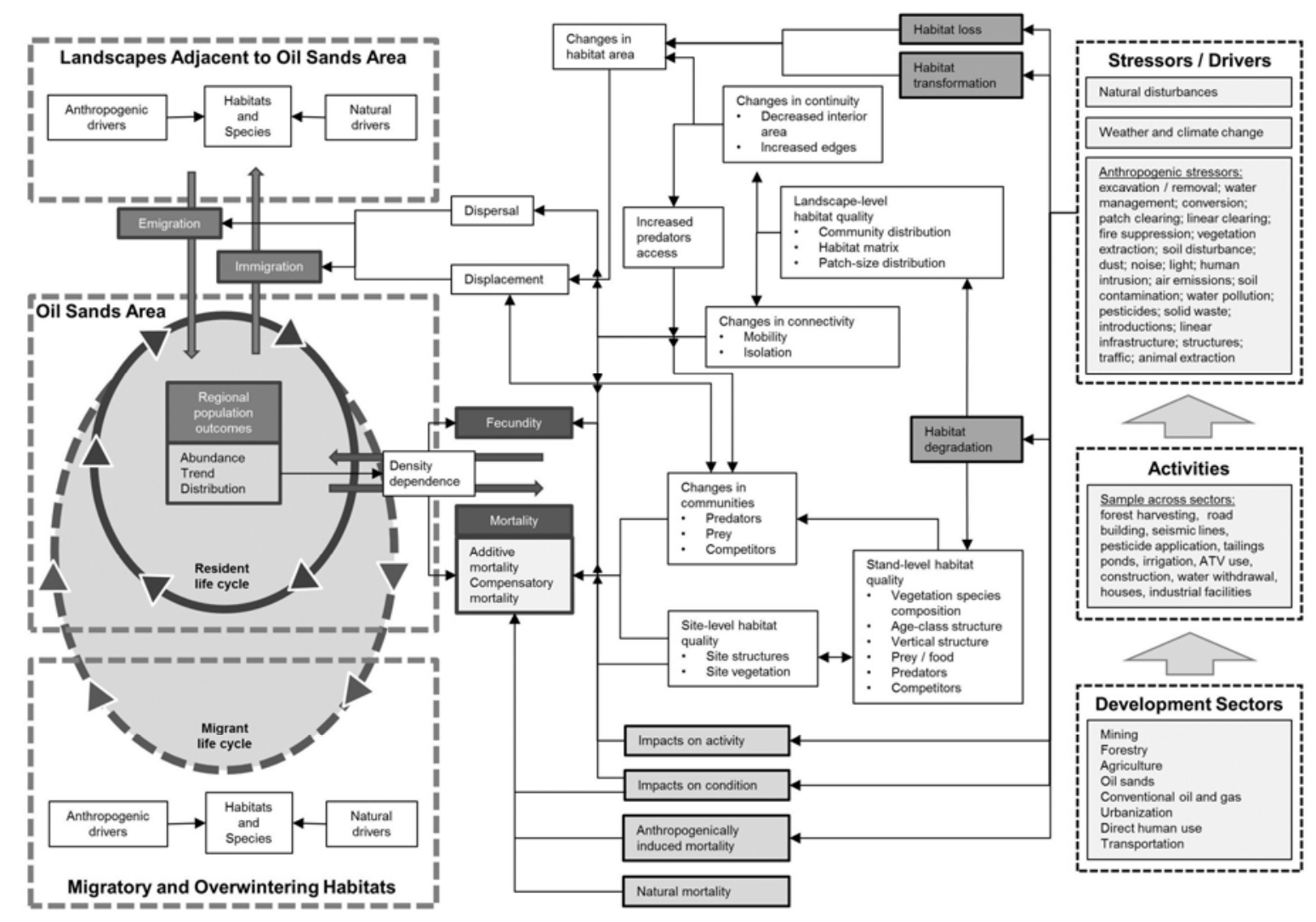

Fig. A1.4. Landscape model representing the dynamics of all terrestrial species occupying the study area. Resident species' outcomes are contained within the dashed box labeled 'Oil Sands Area', while migratory species extend to the lower dash box with the resulting set of additional drivers.

or transformation) or habitat quality (degradation in habitat conditions). Light shaded boxes represent classes of impacts that affect individuals within the population which lead to sub-lethal (impacts on activity or condition) or lethal (natural or anthropogenically induced) effects. These latter impact classes are shown in less detail in part because of space restrictions and because they are expanded upon in subsequent models.

The right portion of the model provides a simplified representation of the source of natural drivers and human influences on population dynamics adapting the IUCN threats classification system (Salafsky and others 2008). At the bottom right, sectors are listed to represent the types of human development occurring in the study area. These sectors are linked, in aggregate, to a subset of examples representing more specific activities within each sector. Activities are then linked to the varied stressors identified in the ecosystem model. A subset of natural drivers is also included to represent their important role as forcing agents on population dynamics. Table A1.3 provides a description and examples of the broad range of stressors across the landscape, while Table A1.4 aligns these stressors with their originating development sectors. To inform development of a monitoring program we characterized the spatio-temporal scales over which these stressors and drivers operate and the many-to-many alignment between sectors and stressors (each sector will result in a variety of stressors associated with its dominant activities and several different sectors may contribute to a similar stressor). 
Table A1.3. Human stressors associated with development sectors affecting migratory bird habitats.

\begin{tabular}{|c|c|c|c|}
\hline $\begin{array}{l}\text { Stressor } \\
\text { Grouping }\end{array}$ & Stressor & Description & Examples \\
\hline \multirow[t]{8}{*}{ Biological } & Patch clearing & $\begin{array}{l}\text { Removal of all major surface vegetation; } \\
\text { polygonal footprint }\end{array}$ & $\begin{array}{l}\text { Clearcut harvesting; also as a precursor to excavation / } \\
\text { removal activities }\end{array}$ \\
\hline & $\begin{array}{l}\text { Linear } \\
\text { clearing }\end{array}$ & $\begin{array}{l}\text { Removal of all major surface vegetation; } \\
\text { linear footprint }\end{array}$ & $\begin{array}{l}\text { Right-of-ways for transportation and utility corridors, } \\
\text { seismic lines }\end{array}$ \\
\hline & Conversion & $\begin{array}{l}\text { Transformation of natural habitat states to a } \\
\text { different though still functioning alternate } \\
\text { habitat state }\end{array}$ & Agricultural lands, urban parks \\
\hline & $\begin{array}{l}\text { Vegetation } \\
\text { extraction }\end{array}$ & Removal of vegetation by humans & $\begin{array}{l}\text { Forest harvesting, silvicultural shrub control, } \\
\text { harvesting of non-timber forest products, grazing, } \\
\text { mowing, cropping, haying }\end{array}$ \\
\hline & $\begin{array}{l}\text { Animal } \\
\text { extraction }\end{array}$ & Removal of animals by humans & $\begin{array}{l}\text { Hunting, fishing, and trapping; control of nuisance } \\
\text { animals }\end{array}$ \\
\hline & Introductions & Introduction of nonnative species & $\begin{array}{l}\text { Invasive plants, invasive animals, nonnative pests, } \\
\text { introduced agricultural crops }\end{array}$ \\
\hline & Pesticides & $\begin{array}{l}\text { Commercial application of herbicides / } \\
\text { insecticides }\end{array}$ & $\begin{array}{l}\text { Agricultural and silvicultural control of weed species } \\
\text { or damage-causing insects }\end{array}$ \\
\hline & $\begin{array}{l}\text { Human } \\
\text { intrusion }\end{array}$ & $\begin{array}{l}\text { Disruption and disturbance due to the } \\
\text { presence of humans on the landscape }\end{array}$ & $\begin{array}{l}\text { Recreational activities, industrial exploration } \\
\text { activities, fire suppression / ignition }\end{array}$ \\
\hline \multirow[t]{4}{*}{ Air } & Emissions & $\begin{array}{l}\text { Air pollution, including toxic emissions, } \\
\text { smoke, smog, greenhouse gases, and } \\
\text { particulate matter }\end{array}$ & $\begin{array}{l}\text { Industrial facilities, power plants, vehicle and } \\
\text { machinery emissions }\end{array}$ \\
\hline & Noise & $\begin{array}{l}\text { Unnatural sources of noise above natural } \\
\text { levels; acute and prolonged sources }\end{array}$ & $\begin{array}{l}\text { Construction activities, industrial machinery, } \\
\text { compressor stations, traffic noise, industrial and urban } \\
\text { noise pollution }\end{array}$ \\
\hline & Light & $\begin{array}{l}\text { Unnatural sources of light above natural } \\
\text { levels; diffuse and point sources }\end{array}$ & $\begin{array}{l}\text { Lights on building and structures, general light } \\
\text { pollution from industrial and urban sources }\end{array}$ \\
\hline & Dust & $\begin{array}{l}\text { Unnatural sources of dust above natural } \\
\text { levels; diffuse and point sources }\end{array}$ & $\begin{array}{l}\text { Road construction, use of unpaved roads, construction } \\
\text { activities }\end{array}$ \\
\hline \multirow[t]{6}{*}{ Land } & $\begin{array}{l}\text { Soil } \\
\text { disturbance }\end{array}$ & $\begin{array}{l}\text { Erosion of soil material due to modification } \\
\text { of stabilizing elements or alteration of } \\
\text { hydrologic processes }\end{array}$ & $\begin{array}{l}\text { Tillage of agricultural fields, compaction by industrial } \\
\text { and agricultural machinery }\end{array}$ \\
\hline & $\begin{array}{l}\text { Soil } \\
\text { contamination }\end{array}$ & $\begin{array}{l}\text { Release and persistence of toxic chemicals } \\
\text { into the soil }\end{array}$ & Hydrocarbons, heavy metals, dioxins \\
\hline & $\begin{array}{l}\text { Linear } \\
\text { infrastructure }\end{array}$ & $\begin{array}{l}\text { Anthropogenic structures with linear } \\
\text { footprint }\end{array}$ & Power lines, above-ground pipelines \\
\hline & Structures & $\begin{array}{l}\text { Anthropogenic structures with polygonal or } \\
\text { linear footprints }\end{array}$ & $\begin{array}{l}\text { Industrial and urban buildings, communication towers, } \\
\text { other structures }\end{array}$ \\
\hline & Traffic & Vehicular traffic along transportation routes & Car and truck traffic, rail traffic \\
\hline & Solid waste & Solid waste entering the landscape & Landfills, illegal dumping, tailings \\
\hline \multirow[t]{2}{*}{ Water } & $\begin{array}{l}\text { Water } \\
\text { management }\end{array}$ & $\begin{array}{l}\text { Withdrawals, diversions or changes in the } \\
\text { timing of flow. No distinction is made } \\
\text { between direct manipulation (e.g., dams) } \\
\text { and indirect manipulation (e.g., oilsands } \\
\text { development). }\end{array}$ & $\begin{array}{l}\text { Dams and reservoirs, water withdrawal and/or } \\
\text { diversion for oilsands processing, wetland drainage, } \\
\text { withdrawal for urban water use }\end{array}$ \\
\hline & $\begin{array}{l}\text { Water } \\
\text { pollution }\end{array}$ & $\begin{array}{l}\text { Water-borne pollution of various sources } \\
\text { and origins }\end{array}$ & $\begin{array}{l}\text { Direct contamination from industrial and urban } \\
\text { sources, direct contamination from pesticides, leaching } \\
\text { from solid waste, collection from surface runoff, } \\
\text { deposition of air-borne particulate matter or acid rain }\end{array}$ \\
\hline
\end{tabular}


Table A1.4. Alignment of development sectors with stressors affecting landscapes of the study area originating from major $(\bullet)$ and minor / conditional sources $(\circ)$.

\begin{tabular}{|c|c|c|c|c|c|c|c|c|c|c|}
\hline \multirow{2}{*}{$\begin{array}{l}\text { Stressor } \\
\text { Grouping }\end{array}$} & \multirow[t]{2}{*}{ Stressor } & \multicolumn{9}{|c|}{ Development Sectors } \\
\hline & & Mining & Forestry & Agriculture & Oil Sands & $\begin{array}{c}\text { Convent'l } \\
\text { Oil and Gas }\end{array}$ & $\begin{array}{l}\text { Urban- } \\
\text { ization }\end{array}$ & Human Use & $\begin{array}{l}\text { Transport- } \\
\text { ation }\end{array}$ & $\begin{array}{l}\text { Distant } \\
\text { Industry }\end{array}$ \\
\hline \multirow{7}{*}{ Biological } & Patch clearing & 0 & $\bullet$ & 0 & 0 & 0 & 0 & & & \\
\hline & Linear clearing & $\circ$ & 0 & & $\bullet$ & $\bullet$ & & 0 & $\bullet$ & \\
\hline & Conversion & & & $\bullet$ & & & $\bullet$ & & & \\
\hline & Biomass extraction & & $\bullet$ & $\bullet$ & & & & $\bullet$ & & \\
\hline & Introductions & & & $\bullet$ & & & $\bullet$ & $\bullet$ & $\bullet$ & \\
\hline & Pesticides & & $\bullet$ & $\bullet$ & & & 0 & & & \\
\hline & Human intrusion & $\bullet$ & $\bullet$ & & $\bullet$ & $\bullet$ & $\bullet$ & $\bullet$ & & \\
\hline \multirow{4}{*}{ Air } & Emissions & $\bullet$ & & 0 & $\bullet$ & $\bullet$ & $\bullet$ & & $\bullet$ & $\bullet$ \\
\hline & Noise & $\bullet$ & & & $\bullet$ & $\bullet$ & $\bullet$ & & $\bullet$ & \\
\hline & Light & & & & $\bullet$ & $\bullet$ & $\bullet$ & & $\bullet$ & \\
\hline & Dust & $\bullet$ & $\bullet$ & 0 & $\bullet$ & $\bullet$ & & $\circ$ & $\bullet$ & \\
\hline \multirow{6}{*}{ Land } & Soil disturbance & $\bullet$ & $\bullet$ & $\bullet$ & $\bullet$ & $\bullet$ & $\bullet$ & 0 & $\bullet$ & \\
\hline & Soil contamination & $\bullet$ & 0 & $\bullet$ & $\bullet$ & $\bullet$ & 0 & & & \\
\hline & Linear infrastructure & $\bullet$ & $\bullet$ & 0 & $\bullet$ & $\bullet$ & $\bullet$ & & $\bullet$ & 0 \\
\hline & Structures & & & & $\bullet$ & $\bullet$ & $\bullet$ & & & \\
\hline & Traffic & $\bullet$ & $\bullet$ & O & $\bullet$ & $\bullet$ & $\bullet$ & 0 & $\bullet$ & \\
\hline & Solid waste & $\bullet$ & & & $\bullet$ & & $\bullet$ & & & \\
\hline \multirow{2}{*}{ Water } & Water management & & & $\bullet$ & $\bullet$ & $\bullet$ & $\bullet$ & & & 0 \\
\hline & Water pollution & $\bullet$ & & $\bullet$ & $\bullet$ & $\bullet$ & $\bullet$ & & & \\
\hline
\end{tabular}




\section{Bird guild models}

Development of the two bird guild models was based on several reports summarizing impacts on boreal forest birds (Blancher 2003; Schneider and Dyer 2006; Wells and others 2008; ABMI 2009b; Cheskey and others 2011; PEG 2011; Environment Canada 2012), as well as other research papers on specific elements within each of the guild models (e.g., see citations in Table A1.5).

A simplified version of the guild model is provided in Fig. A1.5 and follows the broad form of the landscape-level population model (Fig. A1.4). The forest (Fig. A1.6) and wetland-dependent (Fig. A1.7) bird models elaborate on this simplified model. These guilds also align with the upland/forest and lowland/wetland habitat states at the landscape level (Fig. A1.3). The pathways-of-effect were organized somewhat differently across guilds to test equally credible alternative structures. For both guild models, pathways are grouped according to impacts on habitat and impacts on health (activity or condition) and survival. The wetland-dependent bird model explicitly considers impacts on nesting success, where the forest bird model does not.

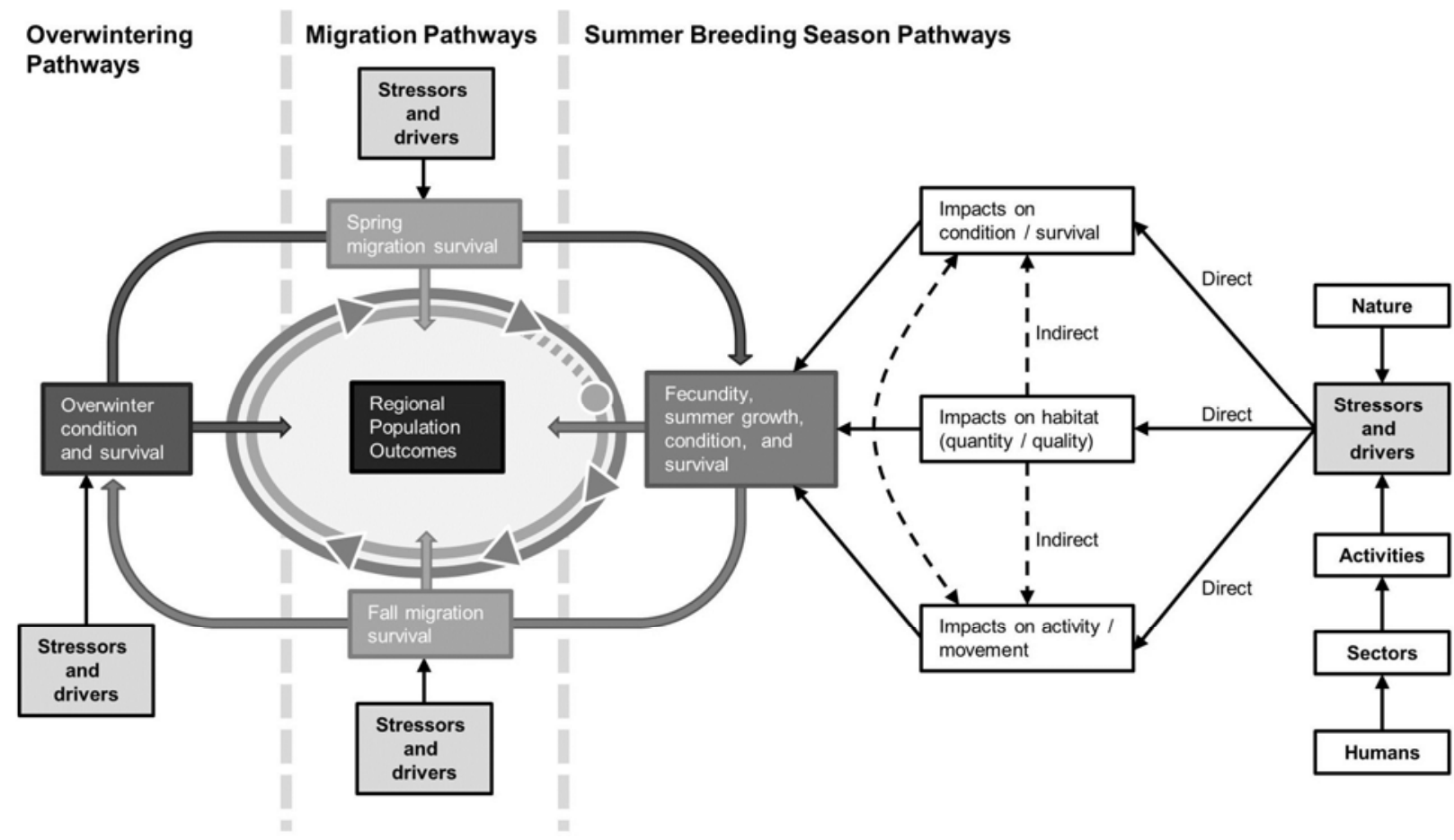

Fig. A1.5. Simplified model illustrating the core components and pathways in the forest and wetland-dependent bird guild models. Of particular importance is that only the 'Summer Breeding Season Pathways' are influenced by the oil sands region, with what are likely significant influences on regional population outcomes during both migration and wintering portions of the lifecycle (Sillet and Holmes 2002; Rockwell and others 2012; Hostetler and others 2015). 
Fig. A1.6.

Conceptual model representing relationships among human stressors / natural drivers, impacts, life stages, and population responses for all forest birds occupying the study area.

Fig. A1.7.

Conceptual model representing relationships among human stressors / natural drivers, impacts, life stages, and population responses for all wetlanddependent birds occupying the study area

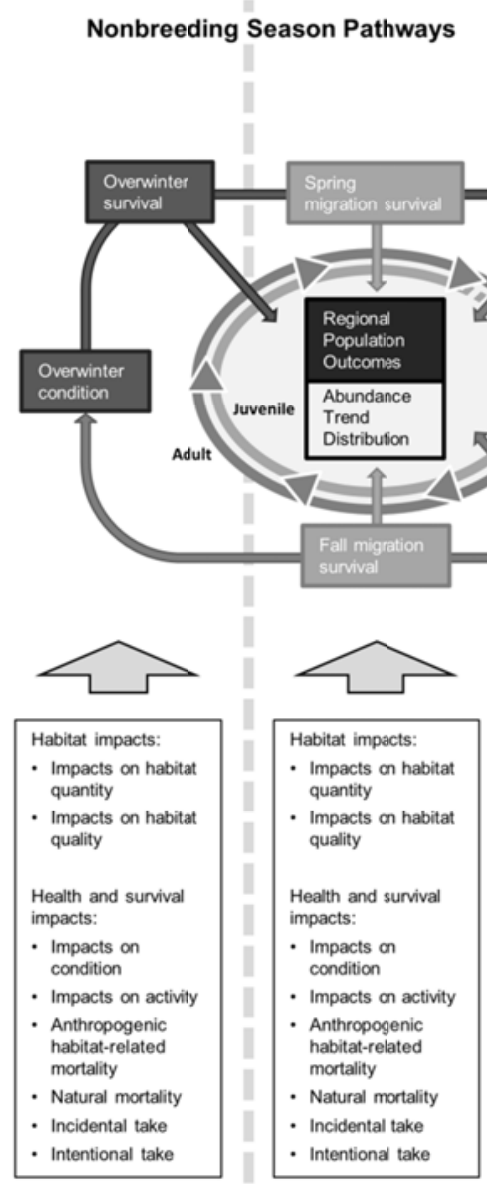

Breeding Season Pathways

Intermediate Outcomes
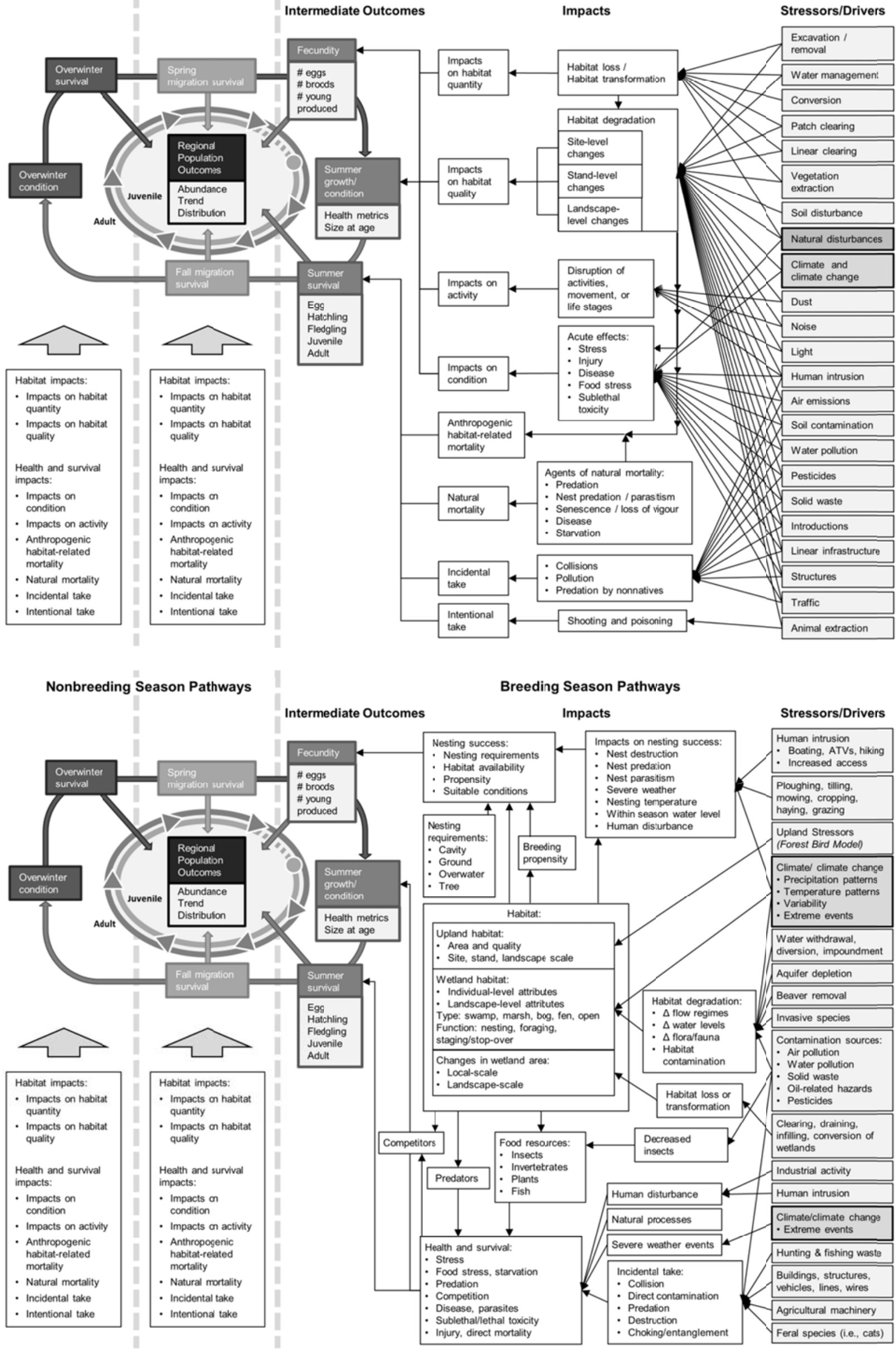
The left part of the models shows an annual life cycle separated into key life stages: breeding, fall migration, overwintering, and spring migration. At the centre are outcomes related to migratory bird populations which represent the most important, relevant, and measurable outcomes for the monitoring program. Regional population measures are the core consideration, as opposed to continental population measures, because many of the species of interest have wide summer breeding ranges that will be subject to different sets of stressors. An inner ring represents juveniles or "hatch year" for the first year of life, though species with delayed maturity would continue to be considered juvenile until they start breeding (represented by thatching of inner circle). An outer ring represents subsequent adult years of life with seven distinct influences: fecundity, summer growth/condition, summer survival, fall migration survival, overwinter condition, overwinter survival, and spring migration survival. Survival and fecundity are direct impacts on populations (arrows to the centre), whereas changes in condition have indirect impacts on populations through their effect on subsequent life stages (arrows to other life stages). For instance, summer growth/condition affects summer survival, fall migration survival and ultimately overwinter condition (denoted by arrow from summer growth to overwinter condition). Alternatively, fecundity is influenced both by the condition that birds are in when they return to the breeding ground from their overwintering grounds (overwinter condition) and the conditions on the breeding grounds themselves.

Stressors and drivers are shown to have potential impacts on summer breeding, migration, and overwintering stages in the middle and left part of the model. For the summer breeding season, stressors and drivers are elaborated upon and shown to be natural (e.g., wildfire or drought) or anthropogenic. Each of the stressors and individual pathways do not necessarily apply to all species, but rather represent drivers of pathways that are relevant to at least a subset of species. These forcings can have direct and indirect impacts on habitats and/or individuals, which ultimately affect migratory bird populations based on a sequence of linkages represented in the models by pathways-of-effect in the breading season (middle portion of model). As noted above, breeding season pathways can be grouped according to their: (1) impact on habitat, (2) impact on health (activity and condition) and survival, and (3) impact on nesting success. Nonbreeding season pathways are not explicitly represented in these models given the geographic focus of the monitoring program, though are expected to result in similar kinds of impacts across migratory and overwintering ranges. 
Impacts on habitat include loss, transformation, and degradation. Loss refers to the complete elimination of habitats. Habitat transformation refers to the alteration from an existing state to an alternative that leads to a change in species composition. For example, the conversion from a forest to a pasture may eliminate occupancy by warblers but increase habitat use by savannah sparrows. Habitat degradation refers to a more subtle, though broader, range of impacts that decrease the quality and suitability of habitats. For instance, selective harvesting has been shown to decrease abundance of ovenbirds likely due to changes in the quality of both the canopy and shrub-layer in harvested stands (Bourque and Villard 2001; Jobes and others 2004). The three impacts to habitat also create complex interactions that are not represented in these models. Similarly, interdependencies among stressors are also not captured to avoid an unnecessarily complex model (e.g., air emissions can lead to water pollution, aquifer depletion may be driven by water withdrawal, diversion and a changing climate). Links from the habitat boxes indicate that changes in habitat quantity and quality can lead to other impacts. As an example, studies have found higher rates of nest predation in forested patches suggesting a possible relationship between forest fragmentation and predation (e.g., Darveau and others 1997; Manolis and others 2002).

Impacts on health include stressors that disrupt or interfere with a species' ability to conduct its normal activities, especially foraging and movement among habitats, or may cause stress, injury, disease, malnutrition, and toxicity, which have an effect on an individual's condition. For instance, disruption of foraging-related activities may result in reduced summer growth/condition as illustrated by discussion in the literature on the importance of high quality wildlife habitats (Thompson 2004). Impacts on health may also be due to changes in habitat caused by other stressors (e.g., changes in habitat that affect food availability which leads to food stress).

Impacts on survival include different sources of natural mortality: predation, senescence/loss of vigour, disease and starvation. Though natural, they can also be substantially altered by humaninduced changes in habitat. This group of impacts includes incidental take - human-induced mortality that is direct and unintentional (e.g., birds killed by colliding with telecommunication towers or cars, see Calvert and others 2013), and intentional take - killing which is deliberate, as in hunting of waterfowl or upland game birds.

Impacts on nesting success are influenced by the availability of appropriate nesting habitat and processes that interfere with successful nesting despite the availability of sites. Interfering 
processes include predation or parasitism of nests, destruction of nests by human actions or severe weather, detrimental changes in habitat conditions, or disturbance from human intrusion. These impacts are important since the disruption of breeding-related activities or disturbance of birds on their nests may lead to reduced fecundity or abandonment. This phenomenon has been observed for a wide variety of species including Bald Eagle (Therres and others 1993), Great Blue Heron (Vennesland 2010), and White-throated Sparrow (Hannah and others 2008).

Due to their breadth, the forest and wetland-dependent bird models lacked the level of specificity necessary for the expert weighting process. Distinct and embedded pathways-of-effect and causal mechanisms affecting life stage and population level responses were pulled from the diagrams and elaborated upon. Eight distinct habitat pathways were identified. Given the geographic scope and emphasis of the monitoring program, pathways leading to human induced mortality (incidental and intentional take) and pathways-of-effect at other life stages, were not included. Table A1.5 provides a summary of each pathway disaggregated according to the drivers, linkages, and outcomes of relevance to migratory birds for which new visualizations were made to present to experts (see example of a single pathway diagrammed in Fig. A1.8). Pathways were distinguished according to their spatial scale of effect (stand vs. landscape level), type of habitat impact (quantity vs. quality) and form of habitat disturbance based on the sector of origin (habitat loss vs. habitat transformation). From the guild models, eleven causal mechanisms were also identified to explicitly recognize the underlying and driving influences that affect the proximate (growth, survival, and fecundity) and ultimate (abundance, trend, distribution) outcomes of interest. Table 2 in the main manuscript lists these causal mechanisms. These pathways and causal mechanisms were the subjects in the prioritization exercise summarized in the main manuscript. 
Table A1.5. Core pathways-of-effect influencing migratory bird habitats across the study area.

\begin{tabular}{|c|c|c|c|c|c|c|c|}
\hline \multirow[t]{2}{*}{ Pathways-of-Effect } & \multicolumn{2}{|c|}{ Drivers $^{\mathrm{a}}$} & \multicolumn{2}{|l|}{ Linkages } & \multicolumn{3}{|c|}{ Outcomes } \\
\hline & Sectors & Stressors & Impacts & Impact Classes $^{\mathrm{b}}$ & Intermediate & Ultimate $^{\mathrm{c}}$ & Examples \\
\hline \multirow{4}{*}{$\begin{array}{l}\text { (A) Stand-level disturbances to forests } \\
\text { due to urbanization, industrial } \\
\text { development, and transportation leading } \\
\text { to habitat losses and potential decreases in } \\
\text { regional populations. }\end{array}$} & OGO & \multirow[t]{4}{*}{ VE } & \multirow{4}{*}{$\begin{array}{l}\text { Such changes reduce habitats for } \\
\text { forest birds, leading to displacement, } \\
\text { competition, and changes in } \\
\text { predation. }\end{array}$} & HQN & \multirow{4}{*}{$\begin{array}{l}\text { Absence of forest birds and local } \\
\text { emigration }\end{array}$} & \multirow[t]{4}{*}{-} & \multirow[t]{4}{*}{ All obligate forest birds } \\
\hline & MIN & & & AHM & & & \\
\hline & TRP & & & $\mathrm{CON}$ & & & \\
\hline & URB & & & & & & \\
\hline \multirow{4}{*}{$\begin{array}{l}\text { (B) Landscape level disturbances to } \\
\text { forests due to urbanization, industrial } \\
\text { development, and transportation leading } \\
\text { to losses and fragmentation of habitats } \\
\text { and potential for negative influences on } \\
\text { regional populations. }\end{array}$} & OGO & \multirow[t]{4}{*}{ VE } & \multirow{4}{*}{$\begin{array}{l}\text { Conversion / fragmentation of forest } \\
\text { reduces habitat for birds and changes } \\
\text { in connectivity / continuity. } \\
\text { Landscape-level impacts are related } \\
\text { in a nonlinear way to the extent of } \\
\text { harvesting. }\end{array}$} & HQN & \multirow{4}{*}{$\begin{array}{l}\text { Landscape-level emigration and } \\
\text { reduced landscape-level populations }\end{array}$} & \multirow[t]{4}{*}{-} & \multirow[t]{4}{*}{ All obligate forest birds } \\
\hline & MIN & & & HQL & & & \\
\hline & TRP & & & AHM & & & \\
\hline & URB & & & & & & \\
\hline \multirow{6}{*}{$\begin{array}{l}\text { (C) A broad range of human activities } \\
\text { leading to localized impacts on habitat } \\
\text { quality which have the potential for } \\
\text { landscape level and cumulative impacts } \\
\text { on habitats and adverse effects on } \\
\text { regional populations. }\end{array}$} & OGO & \multirow{6}{*}{$\begin{array}{l}\text { All of } \\
\text { Table } \\
\text { A1.3 }\end{array}$} & \multirow{6}{*}{$\begin{array}{l}\text { Habitat quality is degraded through } \\
\text { stressors which alter the capacity of } \\
\text { habitats, leading to loss of key site- } \\
\text { level requirements (nesting } \\
\text { structures, perches, cover } \\
\text { vegetation). }\end{array}$} & \multirow[t]{6}{*}{ HQL } & \multirow{6}{*}{$\begin{array}{l}\text { Decreased productive capacity and } \\
\text { reduced condition }\end{array}$} & \multirow[t]{6}{*}{-} & \multirow{6}{*}{$\begin{array}{l}\text { Several species of birds are less } \\
\text { abundant in noisy environments in the } \\
\text { oil sands including white-throated } \\
\text { sparrow, yellow-rumped warbler, and } \\
\text { red-eyed vireo (Bayne and others } \\
2008 \text { ) }\end{array}$} \\
\hline & MIN & & & & & & \\
\hline & TRP & & & & & & \\
\hline & URB & & & & & & \\
\hline & FOR & & & & & & \\
\hline & AGR & & & & & & \\
\hline \multirow{3}{*}{$\begin{array}{l}\text { (D) Stand level transformations of forests } \\
\text { due to agricultural conversion leading to } \\
\text { potential losses / gains and either negative } \\
\text { or positive influences on regional } \\
\text { populations (depending on habitat } \\
\text { preferences). }\end{array}$} & \multirow[t]{3}{*}{ AGR } & \multirow[t]{3}{*}{$\mathrm{CO}$} & \multirow{3}{*}{$\begin{array}{l}\text { Conversion from forested to } \\
\text { nonforested habitats alters the } \\
\text { abundance of food and habitat } \\
\text { attributes leading to fewer forest- } \\
\text { dwelling species and more species } \\
\text { able to use forest edges. }\end{array}$} & \multirow{3}{*}{$\begin{array}{l}\text { HQN } \\
\text { HQL }\end{array}$} & Reduced productivity, emigration, & - & All obligate forest birds \\
\hline & & & & & $\begin{array}{l}\text { and lower density with habitat } \\
\text { decreases }\end{array}$ & & \\
\hline & & & & & $\begin{array}{l}\text { Increased productivity, immigration, } \\
\text { and higher density with habitat } \\
\text { increases }\end{array}$ & + & $\begin{array}{l}\text { American robin associate positively } \\
\text { with forest edges (Hawrot and Niemi } \\
\text { 1996) }\end{array}$ \\
\hline \multirow{2}{*}{$\begin{array}{l}\text { (E) Landscape-level transformations of } \\
\text { forests due to agricultural conversion } \\
\text { leading to fragmentation and losses / } \\
\text { gains of habitats with either negative or } \\
\text { positive influences on regional } \\
\text { populations (depending on habitat } \\
\text { preferences). }\end{array}$} & \multirow[t]{2}{*}{ AGR } & \multirow[t]{2}{*}{$\mathrm{CO}$} & \multirow{2}{*}{$\begin{array}{l}\text { Conversion from forested to } \\
\text { nonforested areas lead to variable } \\
\text { landscape, leading to changes in } \\
\text { habitat connectivity, as well as less } \\
\text { habitat for forest-dwelling species } \\
\text { and more habitat for generalist } \\
\text { species. }\end{array}$} & \multirow[t]{2}{*}{$\begin{array}{l}\text { HQN } \\
\text { HQL }\end{array}$} & $\begin{array}{l}\text { Landscape-level emigration and } \\
\text { reduced landscape-level populations } \\
\text { for birds with decreases in habitat }\end{array}$ & - & All obligate forest birds \\
\hline & & & & & $\begin{array}{l}\text { Landscape-level immigration and } \\
\text { increases in landscape-level } \\
\text { populations for birds with increases } \\
\text { in habitat }\end{array}$ & + & $\begin{array}{l}\text { Corvid density may increase } \\
\text { in fragmented forest (Andrén 1992) }\end{array}$ \\
\hline (F) Stand-level transformations from & $\mathrm{OGO}^{\mathrm{d}}$ & $\mathrm{PC}$ & Shift to regenerating forests alters & HQN & Reduced productivity, local & - & Red-breasted nuthatches prefer large \\
\hline $\begin{array}{l}\text { older to young regenerating forest due to } \\
\text { harvesting leading to either negative or }\end{array}$ & FOR & LC & $\begin{array}{l}\text { abundance of food and habitat } \\
\text { attributes leading to less habitat for }\end{array}$ & HQL & $\begin{array}{l}\text { emigration and reduced local density } \\
\text { for birds with decreases in habitat }\end{array}$ & & $\begin{array}{l}\text { old conifers and would be adversely } \\
\text { affected (Steeger and Hitchcock 1998) }\end{array}$ \\
\hline $\begin{array}{l}\text { populations (depending on habitat } \\
\text { preferences). }\end{array}$ & & & $\begin{array}{l}\text { forests, conifer-dominated uplands) } \\
\text { and more habitat for other species } \\
\text { (early seral, nonforested habitats) }\end{array}$ & & $\begin{array}{l}\text { Increased productivity, local } \\
\text { immigration, and increased local } \\
\text { density for birds with increases in } \\
\text { habitat }\end{array}$ & + & $\begin{array}{l}\text { Early seral species such as song } \\
\text { sparrow are more abundant in young } \\
\text { forests (Lance and Phinney 2001) }\end{array}$ \\
\hline
\end{tabular}




\begin{tabular}{|c|c|c|c|c|c|c|c|}
\hline \multirow[t]{2}{*}{ Pathways-of-Effect } & \multicolumn{2}{|c|}{ Drivers $^{\mathrm{a}}$} & \multicolumn{2}{|l|}{ Linkages } & \multicolumn{3}{|c|}{ Outcomes } \\
\hline & Sectors & Stressors & Impacts & Impact Classes $^{\mathrm{b}}$ & Intermediate & Ultimate $^{c}$ & Examples \\
\hline $\begin{array}{l}\text { (G) Landscape-level transformations from } \\
\text { older to young regenerating forest due to } \\
\text { harvesting leading to fragmentation and } \\
\text { either negative or positive influences on } \\
\text { regional populations (depending on } \\
\text { habitat preferences). }\end{array}$ & $\begin{array}{c}\text { OGO }^{d} \\
\text { FOR }\end{array}$ & $\mathrm{PC}$ & $\begin{array}{l}\text { Shift to regenerating forests leading } \\
\text { to less habitat for some specialists } \\
\text { (preferring contiguous, large interior } \\
\text { forests) and more habitat for } \\
\text { generalists (preferring fragmented, } \\
\text { disturbed, highly variable } \\
\text { landscapes). }\end{array}$ & $\begin{array}{l}\text { HQN } \\
\text { HQL }\end{array}$ & $\begin{array}{l}\text { Landscape-level emigration and } \\
\text { reduced landscape-level populations } \\
\text { for birds with decreases in habitat } \\
\text { Landscape-level immigration and } \\
\text { increases in landscape-level } \\
\text { populations for birds with increases } \\
\text { in habitat }\end{array}$ & - & $\begin{array}{l}\text { Ovenbird abundance has been shown } \\
\text { to be related to landscape } \\
\text { characteristics (Betts and others 2006) } \\
\text { Corvid density may increase } \\
\text { in fragmented forests (Andrén 1992) }\end{array}$ \\
\hline $\begin{array}{l}\text { (H) Transformations of habitats from old } \\
\text { to young regenerating forest due to } \\
\text { changes in forest fire dynamics (i.e., } \\
\text { wildfire, human caused fires, fire } \\
\text { suppression) leading to stand and } \\
\text { landscape level changes with potential } \\
\text { negative or positive influences on } \\
\text { regional populations (depending on } \\
\text { habitat preferences). }\end{array}$ & $\begin{array}{c}\text { FOR } \\
\text { URB } \\
\text { HUM }\end{array}$ & $\begin{array}{c}\text { ND } \\
\text { HI } \\
\text { WC }\end{array}$ & $\begin{array}{l}\text { Alteration in habitats leading to } \\
\text { fewer habitats for some (mature } \\
\text { forest species) and more habitats for } \\
\text { others (early seral species). Fire } \\
\text { suppression may reduce, while } \\
\text { climate change will increase fires, } \\
\text { creating changes in natural dynamics } \\
\text { on landscape. }\end{array}$ & $\begin{array}{l}\text { HQN } \\
\text { HQL }\end{array}$ & $\begin{array}{l}\text { Decreased density for species which } \\
\text { use intact, old forest, increased } \\
\text { density and fecundity for species } \\
\text { which use burned forest, immigration } \\
\text { or emigration depending on species } \\
\text { preferences (both positive and } \\
\text { negative effects) }\end{array}$ & + & $\begin{array}{l}\text { A number of species are more } \\
\text { abundant in unburned than burned } \\
\text { forests (e.g., Northern waterthrush, } \\
\text { red-eyed vireo, see Morissette and } \\
\text { others2002) } \\
\text { Black-backed and three-toed } \\
\text { woodpeckers would immigrate as they } \\
\text { prefer burned habitats (Hoyt and } \\
\text { Hannon 2002) }\end{array}$ \\
\hline
\end{tabular}

Footnotes:

${ }^{a}$ Note use of the following abbreviations: AGR (agriculture), FOR (forestry), HUM (human use), MIN (mining), OGO (oil sands, conventional oil and gas), TRP (transportation), URB (urban), VE (vegetation extraction), CO (conversion), LC (linear clearing), HI (human intrusion), PC (patch clearing), WC (weather and climate), ND (natural disturbance).

${ }^{\mathrm{b}}$ Note use of the following abbreviations: AHM (anthropogenic habitat-related mortality), CON (condition), HQL (habitat quality), and HQN (habitat quantity).

${ }^{c}-$ and + symbols denote the potential for negative and/or positive influences on regional populations.

${ }^{\mathrm{d}}$ Primarily related to seismic lines 


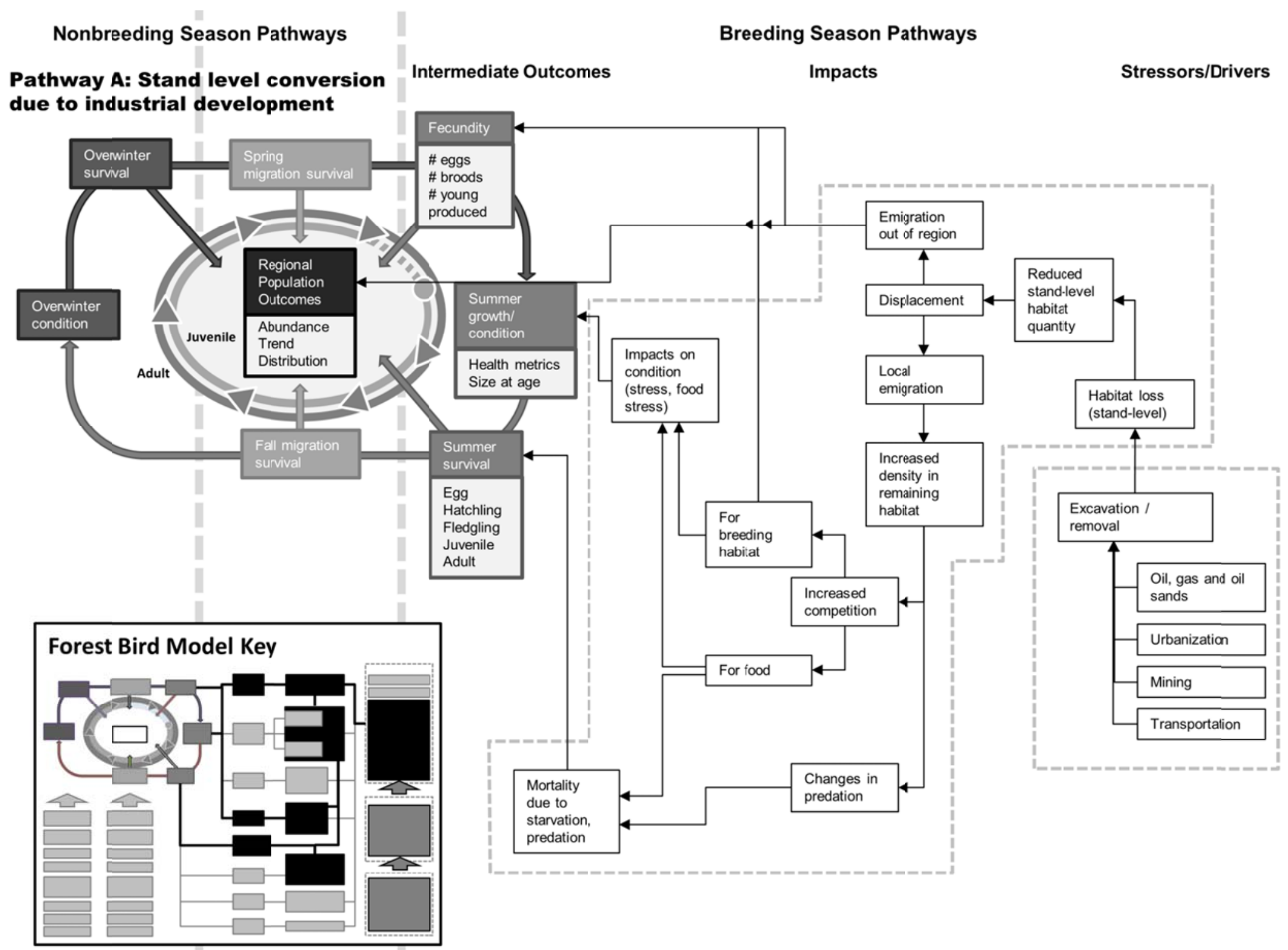

Fig. A1.8. Conceptual model representing habitat pathway A in Table A1.5 for all forest birds across the study area (i.e., stand level conversion due to industrial development). Inset diagram represents the core pathways-of-effect of relevance (in black) from the forest bird model in Fig. A1.6. 


\section{Species models}

Species models were made for Canada Warbler (Cardellina canadensis), Horned Grebe (Podiceps auritus), Swamp Sparrow (Melospiza georgiana), Barn Swallow (Hirundo rustica), Common Nighthawk (Chordeiles minor), Olive-sided Flycatcher (Contopos cooperi), Rusty Blackbird (Euphagus carolinus), Whooping Crane (Grus americana), and Yellow Rail (Coturnicops noveboracensis). This mix of species was selected to illustrate the range of potential effects of human development on bird populations within the study area, especially on Species At Risk. These models were based on COSEWIC Assessment Reports (e.g., Government of Canada 2013b), Alberta Breeding Bird Atlas (FAN 2007), and Birds of North America Online (Cornell Lab of Ornithology 2013), primary literature and expert judgements. Conceptual models for Canada Warbler and Horned Grebe are provided here. Pathways are numbered to correspond with the full suite of hypotheses that have been identified as having an influence on abundance, trend, or distribution of relevant species (see Tables A1.6, A1.7). Details are only presented here for the first two species, but similar information was prepared for the remainder. The conceptual models (diagrams and supporting text) for the latter species are available from the authors or through Research Gate (https://www.researchgate.net/publication/281112203_Conceptual_models_of migratory birds and human development_as_relevant to the oil_sands_of_Canada).

A dramatic decline in abundance of Canada Warbler since the late-1960s has intensified in recent decades leading to its listing as a "Threatened" species (COSEWIC 2008). Though the underlying causes of the decline are not known (Venier and others 2012), Fig. A1.9 summarizes the full range of pathways that are known to influence Canada Warbler populations. Direct habitat loss (HL), habitat transformation (HT), and habitat degradation through landscape level alterations (LC), changes in the shrub layer (SL) and increases in noise (NS) are identified as disturbances to breeding habitats that will ultimately affect fecundity and growth / condition of individuals. These disturbances originate from human development activities (e.g., forestry, agriculture, oil and gas exploration, urbanization) that remove, clear, and/or convert the forested landscape. Moreover, the associated changes in breeding habitats may alter insect abundance (IA) or affect rates of nest parasitism (NP) which can have direct effects on summer survival. Lastly, mortality along migratory flyways from various human sources (MH) and widespread loss and transformation of habitat in its wintering range $(\mathbf{O H})$ as a result of intensive human development in the mountain rainforests of northwestern South America are noted as additional pathways that have direct effects on survival during these life stages.

A persistent decline since the mid-1960s, with rapid declines noted more recently, have led to western population of Horned Grebe being listed as a species of "Special Concern" (COSEWIC 2009). Fig. A1.10 illustrates the pathways-of-effect and interactions among the potential causal mechanisms that are known to 
influence Horned Grebe populations. Core pathways include habitat losses through permanent $(\mathbf{P W})$ and temporary (TW) disturbances to wetlands, as well as the degradation of nesting sites through eutrophication of wetlands due to application of fertilizers (DW) and flooding of nesting sites due to extreme weather during the breeding season (WX). Habitat alterations from human activities also have the potential to affect the abundance of other species which can lead to increases in predation (IP) on all breeding stages (nest, juvenile, and adults) and displacement of adults by competitors (DC). Release of contaminants into waterways from human sources can have toxic effects (TX) and ongoing changes in the incidence of disease (DS) can have impacts on summer survival. During migration additional mortality due to fishing gear entanglement (FG), disease (DS) and extreme weather (WX) can have adverse population level effects. Finally, Horned Grebe is also vulnerable to marine oil spills (MS) and changes in marine prey (MP) in its wintering range. 
Table A1.6. Summary of core pathways-of-effect hypothesized as affecting population level status of Canada Warbler (CAWA) in the study area. Letters refer to notations of pathways in Fig. A1.9.

(HL) Habitat Loss: Urbanization, transportation, and oil \& gas developments contribute to the loss of habitats through the removal of vegetation. In western Canada, forests have been significantly removed due to oil and gas activities (Cooper and others 1997; Senate Subcommittee on the Boreal Forest 1999; Hobson and others 2002; South Peace Bird Atlas Society 2006). The resulting changes can impact fecundity through loss of breeding areas and summer growth/condition through loss of foraging areas. Stand-level changes will also have cumulative effects at the landscape-level.

(HT) Habitat Transformation: Conversion from expanding agriculture and urbanization result in transformation of deciduous and mixedwood forests to other habitats unsuitable for CAWA (Senate Subcommittee on the Boreal Forest 1999; Hobson and others 2002). Patch clearing from forestry and linear clearing from oil and gas exploration can further alter the successional stage of forests, decreasing the amount of mid- or late-seral stages (Senate Subcommittee on the Boreal Forest 1999; Schneider and others 2003). For instance, industrial development in northern Alberta may eliminate old-growth softwood stands within 20 years and old-growth hardwood stands within 65 years (Schneider and others 2003). The resulting decrease in stand-level habitats can have impacts on fecundity and summer growth/condition as well as lead to cumulative effects at the landscape-level (e.g., fragmentation of habitats and increases in forest edges).

(LC) Landscape-Level Changes: As discussed above, changes in stand-level habitat will lead to cumulative effects at the landscape-level. Such habitat fragmentation will also occur due to linear clearing from oil and gas exploration. These changes may increase the shrub layer, but also increase opportunities for nest parasitism. CAWA is relatively tolerant of habitat discontinuity associated with forestry (Schmiegelow and others 1997), but relatively intolerant when associated with agriculture (Robbins and others 1989; Hobson and Bayne 2000). Other research has shown that the occurrence of CAWA is negatively affected by the proximity and length of paved roads within its breeding habitat (Miller 1999). These changes may influence population status as road development is expected to increase substantially in the boreal mixedwood forests of northern Alberta over the coming years (Schneider and others 2003).

(NS) Noise: Although COSEWIC (2008) does not describe noise as a disturbance to CAWA, it is a plausible stressor based on research for other boreal passerines in Alberta (Habib and others 2007; Bayne and others 2008) and other boreal birds in Ontario (Summers and others 2011). Noise may result from numerous activities associated with urbanization, transportation, and oil and gas development (e.g., construction, road traffic, compressor stations). Noise can affect fecundity or summer growth/condition through a direct disruption of normal breeding and foraging activities. For instance, Habib and others (2007) found that ovenbird pairing success was lower near compressor stations than noise-less wellpads. They hypothesized that compressor noise interfered with females' ability to hear males' songs over longer distances or distorted the song so females incorrectly perceived males to be of lower quality.

(SL) Shrub Layer: Naturally forming canopy gaps due to natural disturbance or regenerating forests following harvesting contribute to development of the shrub layer. This habitat is critical for CAWA foraging. In western Canada, local concentrations of suitable habitat were associated with old growth deciduous forests, particularly near small, incised streams at the local scale, and a deciduous forest matrix at the landscape scale (Ball and others 2013). Though increases in forest edges due to harvesting may increase shrub habitats, some silvicultural practices can limit shrub development (Askins and Philbrick 1987; Gauthier and Aubry 1996; Cooper and others 1997; Norton and Hannon 1997; Schieck and others 2000; Tittler and others 2001). As well, grazing by ungulates can reduce the shrub layer and affect habitat quality for CAWA (Conway 1999).

(IA) Insect Abundance: Decreases in insect abundance may impact summer survival, fecundity and growth/condition due to a decrease in food resources. As well, insect abundance depends on a well-developed shrub layer and is further affected by periodic, natural insect outbreaks. CAWA feed primarily on flying insects and spiders in the shrub layer (Conway 1999). Canada Warbler may feed heavily on spruce budworm during outbreaks though they are not considered a spruce budworm specialist (Crawford and Jennings 1989; Patten and Burger 1998; Conway 1999; Sleep and others 2009). It has been suggested that decline of CAWA may be associated with the coinciding decline in spruce budworm outbreaks (Sleep and others 2009), but more recent research indicates little evidence of such a relationship (Venier and others 2012).

(NP) Nest Parasitism: Habitat fragmentation and creation of forest edges tend to increase opportunities for nest parasitism, resulting in decreased summer survival of young CAWA as young cowbirds outcompete them for food brought to the nest. Although CAWA is a common cowbird host its significance is unknown in Alberta (Reitsma and others 2010).

(MH) Migratory Habitat: COSEWIC (2008) does not discuss threats to CAWA during its migration, but it is plausible that it may be vulnerable to impacts on habitats along its migration. Migratory habitats in Central America are similar to its overwintering habitats in South America and expected to be exposed to similar human development pressures.

$(\mathrm{OH})$ Overwintering Habitat: Extensive human development has led to substantial impacts on CAWA's overwintering habitat in South America. Overwintering grounds in the northern Andes include the most threatened forests in the world (Davis and others 1997). Since the 1970 s, $90 \%$ of rainforests and $95 \%$ of cloud forests have been lost, while remaining forests are heavily disturbed (Henderson and others 1991). Such impacts will affect overwinter condition and survival. 


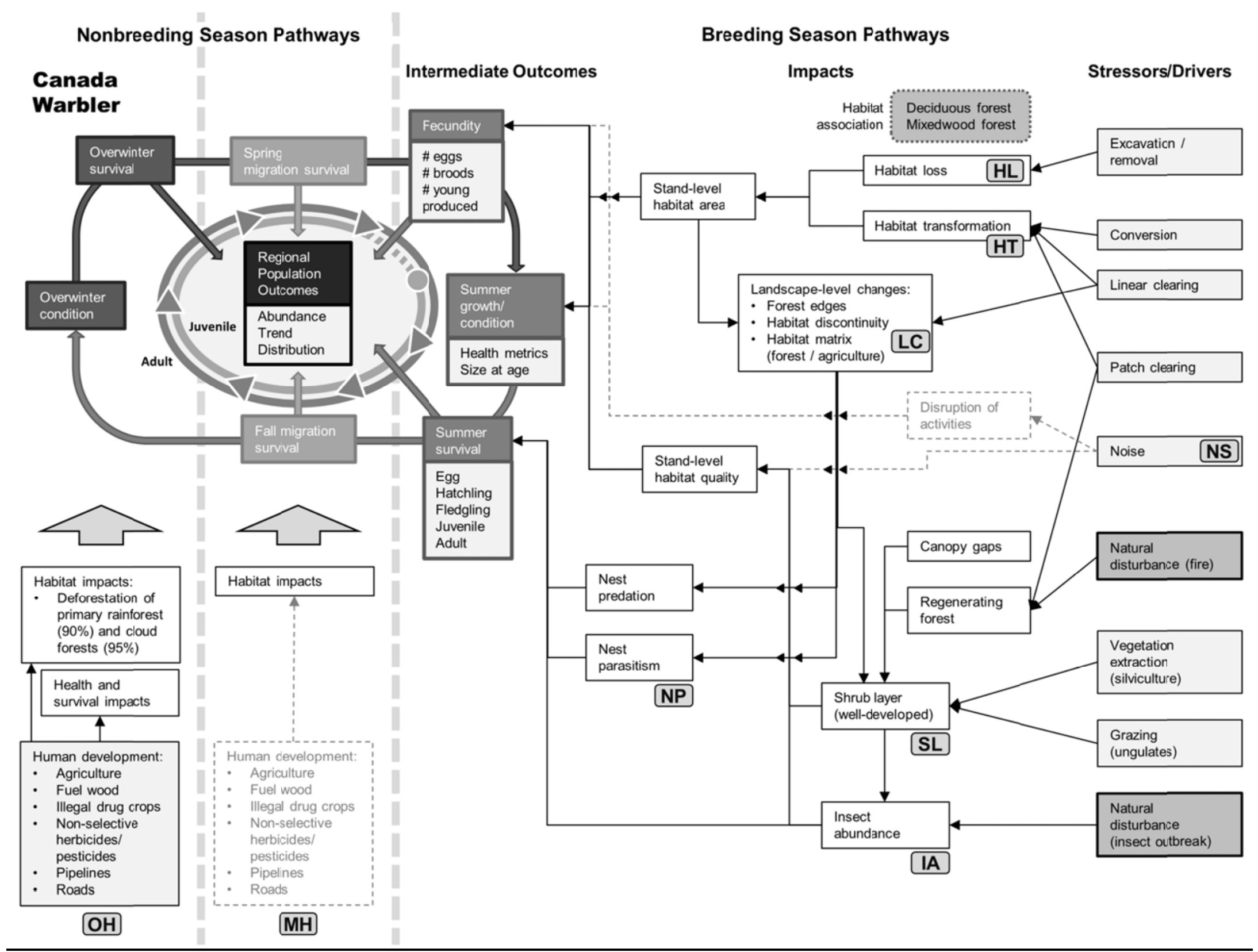

Fig. A1.9. Conceptual model representing the pathways-of-effect influencing population status of Canada Warbler. Letter notations correspond to pathways described in Table A1.6. See Table A1.4 for alignment of stressors presented here with development sectors from study area. 
Table A1.7. Summary of core pathways-of-effect hypothesized as affecting population level status of Horned Grebe (HOGR) in the study area. Letters refer to notations of pathways in Fig. A1.10.

(IP) Increased Predation: A major expansion in range and/or increase in abundance of some predators may be threatening HOGR. Raccoon, Common Raven, Black-billed Magpie, and various gull species take eggs; Northern Pike and gulls can prey on chicks; and minks and possibly foxes prey on adults (Ferguson 1977; Fournier and Hines 1999; Stedman 2000). Raccoons are believed to be spreading into northeastern Alberta (Latham 2008). Breeding Bird Survey observations indicate the abundance of Common Raven has increased substantially in Alberta and across Canada over the past several decades (CWS 2014) with increases in relative abundance also being detected in the study area (FAN 2007).

(PW) Permanent Loss of Wetlands: The clearing, draining, infilling, and conversion of wetlands for human development (e.g., agricultural, rural, industrial, and urban activities) results in the permanent loss of wetlands, thus eliminating the productive potential of such habitats. The cumulative loss of wetlands at a landscape scale may result in a disproportionately greater loss of avian productivity resulting from decreases in nesting density (Andrén 1994).

(TW) Temporary Loss of Wetlands: Drought can lead to the temporary loss of breeding ponds. Although drought is a natural part of climate cycles, the frequency, intensity and duration is expected to increase with climate change. Moreover, HOGR may be additionally sensitive to these losses when combined with permanent losses across the landscape.

(DS) Disease: Type E Botulism may be a significant source of mortality for population exposed to outbreaks. HOGR were among the most affected species in several outbreaks in the Great Lakes (USGS 2007; USGS 2008).

(DW) Eutrophication and Degradation of Wetlands: The accumulation of fertilizers from agricultural activities can lead to eutrophication, contamination and an overall degradation of wetlands (COSEWIC 2009).

(TX) Toxicity: HOGR are vulnerable to contaminant releases, especially through bioaccumulation since they are at a high tropic level in the food chain. Elevated levels of DDE, PCBs, dioxins, and furans have been detected in HOGR (Vermeer and others 1993; Forsyth and others 1994).

(DC) Displacement by Competitors: HOGR may be displaced from breeding ponds by both Pied-billed Grebes and Rednecked Grebes (COSEWIC 2009). Pied-billed Grebes have been increasing in western Canada over the past two decades, with substantial increases in Alberta during last decade (CWS 2014), though decreases in their relative abundance in the study area have also been detected (FAN 2007).

(MP) Changes in Marine Prey: Due to shifts in ocean regimes and changes in human stresses, populations of forage fish and other marine prey species along the coast have changed considerably in recent decades (e.g., Anderson et al 2009; Therriault et al 2009). Changes in marine prey in the wintering range may affect overwinter survival and movement.

(MS) Marine Oil Spills: During overwintering, HOGR spend the majority of its time on the water and is therefore vulnerable to marine oil spills. Mortalities due to oil spills have been document in numerous cases (COSEWIC 2009). Hundreds or thousands have been killed in individual oil spills, sometimes representing substantial portions of all species oiled (del Hoyo and others 1992; Stedman 2000; COSEWIC 2009). Though HOGR are likely vulnerable to oil spills across the entire northern hemispheric range, their expansive overwintering range may offer some protection against catastrophic losses from individual events (Stedman 2000).

(FG) Entanglement in Commercial Fishing Gear: HOGR can get entangled in fishing nets and drown (Harrison and Robins 1992), particularly on large lakes during migration (Riske 1976; Piersma 1988; Ulfvens 1989). Although there are documented cases of HOGR in marine bycatch, there is little evidence of fishing net mortality in North American marine environments during the winter (COSEWIC 2009).

(WX) Severe Weather: The combination of increased rainfall and wind during storm events can result in flooding of floating nests in the breeding season (Shaffer and Laporte 2003). Severe storms have also occasionally been documented to have detrimental impacts during their migration (COSEWIC 2009). 


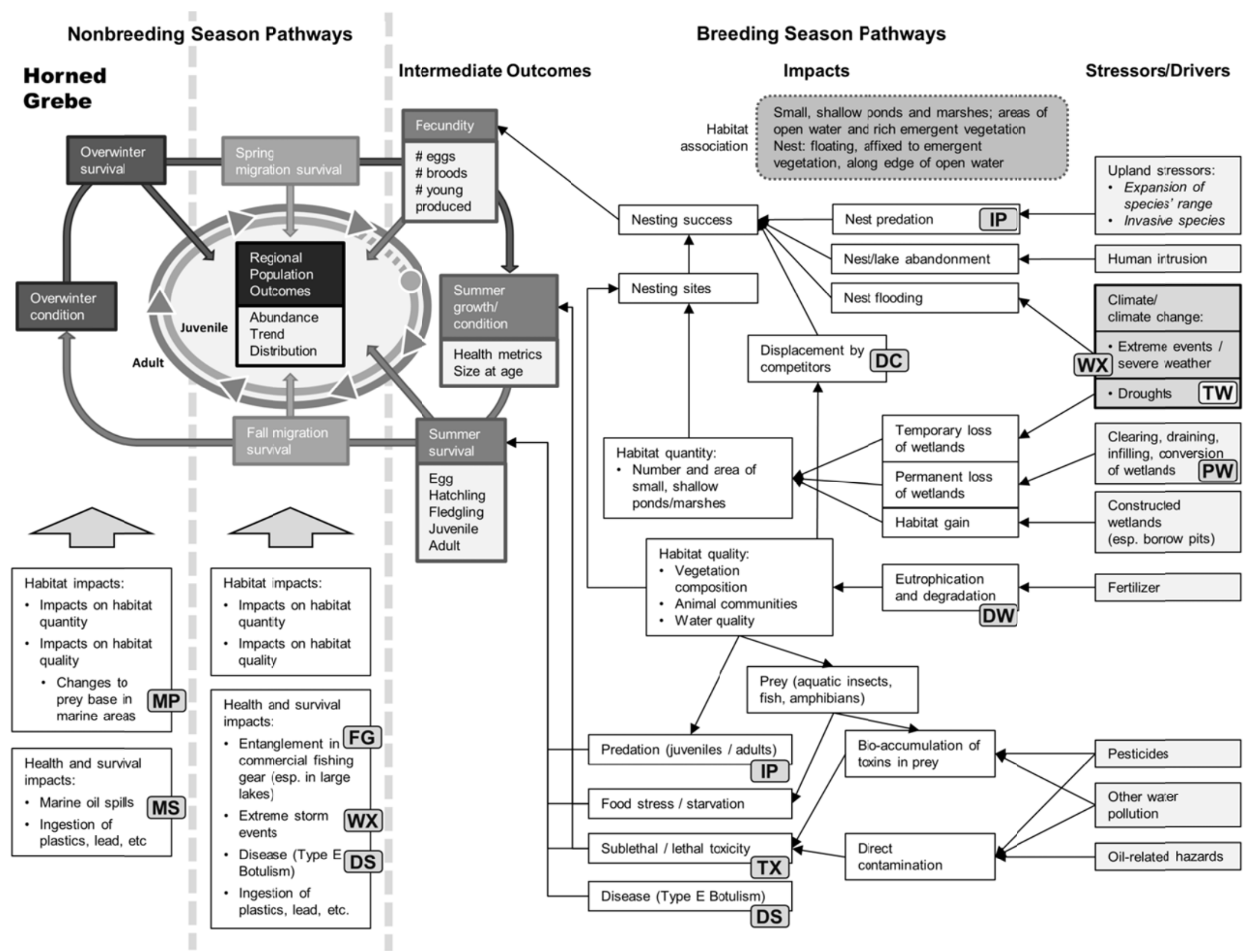

Fig. A1.10. Conceptual model representing the pathways-of-effect influencing population status of Horned Grebe. Letter notations correspond to pathways described in Table A1.7. See Table A1.4 for alignment of stressors presented here with development sectors from study area. 


\section{LITERATURE CITED}

Alberta Biodiversity Monitoring Institute [ABMI] (2009a) ABMI's habitat pyramid: Definitions and element lists. (20039), Version 2009-04-20. Edmonton, AB

Alberta Biodiversity Monitoring Institute [ABMI] (2009b) ABMI species pyramid: Guild definitions and species lists, Version 2009-12-22. Edmonton, AB

Alberta Biodiversity Monitoring Institute [ABMI] (2010) Human disturbance footprint map. Version 1.1. http://www.abmi.ca/home/data/gis-data/human-footprintdownload.html?scroll=true Accessed 20 March 2015, but v1.1 has been updated.

Alberta Sustainable Resource Development [ASRD] (2002) Fort McMurray-Athabasca oil sands: Subregional integrated resource plan. Government of Alberta, Edmonton, AB

Anderson EM, Bower JL, Nysewander DR, Evenson JR, Lovvorn JR (2009) Changes in avifaunal abundance in a heavily used wintering and migration site in Puget Sound, Washington, during 1966-2007. Mar Ornithol 37: 19-27

Andrén H (1992) Corvid density and nest predation in relation to forest fragmentation: A landscape perspective. Ecol 73: 794-804

Andrén H (1994) Effects of habitat fragmentation on birds and mammals in landscapes with different proportions of suitable habitat: A review. Oikos 71(3): 355-366

Askins RA, Philbrick MJ (1987) Effect of changes in regional forest abundance on the decline and recovery of a forest bird community. Wilson Bull 99: 7-21

Ball JR, Solymos P, Bayne EM, Habib T, Stepnisky D, Mahon CL, Schmiegelow F, Song S, Cumming S. (2013) Determination of Habitat associations and Development of Best Management Practices for Canada Warblers in Mixed-Wood Boreal Forests in Alberta. Technical report. Habitat Stewardship Program for species at Risk. Government of Canada.

Bayne EM, Habib L, Boutin S (2008) Impacts of chronic anthropogenic noise from energysector activity on abundance of songbirds in the boreal forest. Conserv Biol 22 (5):1186-1193

Betts MG, Forbes GJ, Diamond AW, Taylor PD (2006) Independent effects of fragmentation on forest songbirds: An organism-based approach. Ecol Appl 16:1076-1089

Blancher P (2003) The importance of Canada's boreal forest to landbirds. Canadian Boreal Initiative and the Boreal Songbird Initiative

Bourque J, Villard MA (2001). Effects of selection cutting and landscape-scale harvesting on the reproductive success of two Neotropical migrant bird species. Conservation Biology 15:184195. 
Britten M, Schweiger EW, Frakes B, Manier D, Pillmore D (2007) Rocky Mountain network vital signs monitoring plan. Natural Resource Report NPS/ROMN/NRR-2007/010. National Park Service, Fort Collins, Colorado

Calvert AM, Bishop CA, Elliot RD, Krebs EA, Kydd TM, Machtans CS, Robertson GJ (2013) A synthesis of human-related avian mortality in Canada. Avian Conserv and Ecol 8(2):11.

Canadian Wildlife Service [CWS] (2014) Migratory birds conservation, monitoring and reporting. http://www.ec.gc.ca/ron-bbs/P001/A001/?lang=e Accessed 20 March 2015

Cheskey E, Wells J, Casey-Lefkowitz S (2011) Birds at risk: The importance of Canada's boreal wetlands and waterways. Natural Resources Defense Council, New York, NY

Ciborowski JJH, Kang M, Grgicak-Mannion A, Raab D, Bayley SE, Foot AL (2013) Synthesis: Applying the reference condition approach for monitoring reclamation areas in the Athabasca oil sands region. Report 2010-0025 prepared for the Cumulative Environmental Management Association. Wood Buffalo, AB

Committee on the Status of Endangered Wildlife in Canada [COSEWIC] (2008) COSEWIC assessment and status report on the Canada Warbler Wilsonia Canadensis in Canada. Ottawa, ON. http://www.registrelep-sararegistry.gc.ca/default e.cfm Accessed 20 March 2015

Committee on the Status of Endangered Wildlife in Canada [COSEWIC] (2009) COSEWIC assessment and status report on the Horned Grebe Podiceps auritus, Western population and Magdalen Islands population, in Canada. Ottawa, ON.

http://www.sararegistry.gc.ca/document/default_e.cfm?documentID=1804 Accessed 20 March 2015

Conway CJ (1999) Canada Warbler (Wilsonia canadensis) In: Poole A, Gill F (eds.) The Birds of North America, No. 421. The Birds of North America, Inc., Philadelphia, PA

Cooper JM, Enns KA, Shepard MG (1997) Status of the Canada Warbler in British Columbia. Wildlife Working Report No. WR-81. Ministry of Environment, Land and Parks, Wildlife Branch, Victoria, BC

Cornell Lab of Ornithology (2013) The Birds of North America Online. Cornell Lab of Ornithology and the American Ornithology Union. http://bna.birds.cornell.edu/bna Accessed 20 March 2015

Crawford HS, Jennings DT (1989) Predation by birds on spruce budworm Choristoneura fumiferana: Functional, numerical and total responses. Ecol 70: 152-163

Cumulative Environmental Management Association [CEMA] (2008) Terrestrial ecosystem management framework for the Regional Municipality of Wood Buffalo. Sustainable Ecosystem Working Group, Fort McMurray, AB 
Darveau M, Bélanger L, Huot J, Mélançon É, DeBellefeuille S (1997) Forestry practices and the risk of bird nest predation in a boreal coniferous forest. Ecological Applications 7:572-580.

Davis SD, Heywood VH, Herrera-MacBryde O, Villa-Lobos J, Hamilton A (1997) Centres of plant diversity: A guide and strategy for their conservation, Volume 3: The Americas. IUCN Publications Unit, Cambridge, England.

del Hoyo J, Elliot A, Sargatal J (1992) Handbook of the birds of the world. Volume 1: Ostrich to ducks. Lynx Edicions, Barcelona

Demarchi DA (2010) Boreal plains ecoprovince. Version 2.2. February 2010

Environment Canada (2011) Integrated monitoring plan for the oil sands, terrestrial biodiversity component. Government of Canada, Ottawa, ON. Cat. No. En14-48/2011E-PDF

Environment Canada (2012) Bird conservation strategy for Bird Conservation Region 6, Prairie and Northern Region: Boreal taiga plains. DRAFT: 24 September 2012 version. Government of Canada

Federation of Alberta Naturalists [FAN] (2007) The atlas of breeding birds of Alberta: A second look. Federation of Alberta Naturalists. Edmonton, AB

Ferguson RS (1977) Adaptations of the Horned Grebe for breeding in Prairie Pothole marshes. Master's Thesis, University of Manitoba, Winnipeg.

Fischenich JC (2008) The application of conceptual models to ecosystem restoration. Ecosystem Management and Restoration Research Program. Technical Note: ERDC/EBA TN-08-1.

Forsyth DJ, Martin PA, De Smet KD, Riske ME (1994) Organochlorine contaminants and eggshell thinning in grebes from prairie Canada. Environ Pollut 85: 51-58

Fournier MA, Hines JE (1999) Breeding ecology of the Horned Grebe Podiceps auritus in subarctic wetlands. Occasional Paper No. 99. Canadian Wildlife Service.

Frid L, Daniel C (2012) Development of a state-and-transition model in support of reclamation planning. Report 2012-005 prepared for the Cumulative Environmental Management Association. Wood Buffalo, AB

Gauthier J, Aubry Y (1996) Les oiseaux nicheurs du Québec: Atlas des oiseaux nicheurs du Québec méridional. Association québécoise des groups d'ornithologues, Société québécoise de protection des oiseaux, Service Canadien de la faune, Environnement Canada, Montréal, PQ

Government of Alberta (2011) Draft lower Athabasca regional plan 2011-2021. Government of Alberta, Edmonton, AB

Government of Alberta (2013) Canada/Alberta implementation plan for oil sands monitoring: The implementation plan, progress report 2012-2013. Edmonton, AB 
Government of Canada (2013b) Committee on the Status of Endangered Wildlife in Canada (COSEWIC). http://www.cosewic.gc.ca/eng/sct5/index_e.cfm Accessed 20 March 2015

Grant WE, Pedersen EK, Marin SL (1997) Ecology and natural resource management: Systems analysis and simulation. John Wiley \& Sons. New York, NY

Habib L, Bayne EM, Boutin S (2007) Chronic industrial noise affects pairing success and age structure of ovenbirds Seiurus aurocapilla. J Appl Ecol 44 (1): 176-184

Halsey LA, Vitt DH, Beilman D, Crow S, Mehelcic S, Wells R (2004) Alberta Wetland Inventory Classification System, Version 2.0. Alberta Sustainable Resource Development, Government of Alberta, Edmonton, AB

Hannah, KC, Schmiegelow FKA, Aitken KEH (2008) White-throated Sparrow response to forest harvesting in north-central Alberta: Results not so clear-cut? Avian Conserv and Ecol 3(1):6

Harrison N, Robins M (1992) The threat from nets to seabirds. RSPB Conserv Rev 6: 51-56

Hawrot RY, Niemi GJ (1996) Effects of edge type and patch shape on avian communities in a mixed conifer-hardwood forest. The Auk 113(3):586-598

Henderson A, Churchill SP, Luteyn JL (1991) Neotropical plant diversity. Nature 351: 21-22

Hobson KA, Bayne E (2000) Effects of forest fragmentation by agriculture on avian communities in the southern boreal mixedwoods of western Canada. Wilson Bull 112: 373387

Hobson KA, Bayne E, Van Wilgenburg SL (2002) Large-scale conversion of forest to agriculture in the boreal plains of Saskatchewan. Conserv Biol 16: 1530-1541

Hobson KA, Schieck J (1999) Changes in bird communities in boreal mixedwood forest: Harvest and wildfire effects over 30 years. Ecol Appl 9: 849-863

Hoyt JS, Hannon SJ (2002) Habitat associations of black-backed and Three-toed Woodpeckers in the boreal forests of Alberta. Can J For Res 32: 1881-1888

Jobes AP, Nol E, Voigt DR (2004) Effects of selection cutting on bird communities in contiguous eastern hardwood forests. J Wildl Manag 68(1): 51-60

Jorgensen SE (1988) Fundamentals of ecological modelling. Elsevier Publishers

Lance AN, Phinney M (2001) Bird responses to partial retention timber harvesting in central interior British Columbia. For Ecol Manag 142 (1-3): 267-280

Latham ADM (2008) Evidence of raccoon, procyon lotor, range extension in northern Alberta. Can Field-Natur 122(2): 176-178

Manolis J, Andersen DE, Cuthbert FJ (2002) Edge effect on nesting success of ground nesting birds near regenerating clearcuts in a forest-dominated landscape. The Auk 119(4): 955-970 
Hostetler JA, Sillet TS, Marra PP (2015). Full-annual-cycle population models for migratory birds. The Auk, Ornithological Advances 132:433-449.

Miller NA (1999) Landscape and habitat predictors of Canada Warbler (Wilsonia canadensis) and Northern Waterthrush (Seiurus noveboracensis) occurrence in Rhode Island swamps (Masters thesis). University of Rhode Island, Kingston, RI

Morissette JL, Cobb TP, Brigham RM, James PC (2002) The response of boreal forest songbird communities to fire and post-fire harvesting. Can J For Res 32: 2169-2183

Natural Regions Committee (2006) Natural regions and subregions of Alberta. Compiled by Downing DJ and Pettapiece WW. Government of Alberta, Edmonton, AB

Noon BR (2002) Conceptual issues in monitoring ecological resources. In: Busch DE and Trexler JC. Monitoring Ecosystems: Interdisciplinary approaches for evaluating ecoregional initiatives. Island Press, Washington, USA

Norton MR, Hannon SJ (1997) Songbird response to partial-cut logging in the boreal mixedwood forest of Alberta. Can J For Res 27:44-53

Patten MA, Burger JC (1998) Spruce budworm outbreaks and the incidence of vagrancy in eastern North American wood-warblers. Can J Zool 76:433-439

Pew Environment Group [PEG] (2011) A forest of blue: Canada's boreal. Pew Environment Group, Seattle, WA http://www.pewenvironment.org/news-room/reports/a-forest-of-bluecanadas-boreal-328843 Accessed 20 March 2015

Piersma T (1988) Body size, nutrient reserves and diet of Red-necked and Slavonian Grebes Podiceps grisegena and P. auritus on Lake Ijsselmeer, the Netherlands. Bird Study 35: 13-24

Reitsma, L, Goodnow M, Hallworth MT, Conway CJ (2010) Canada Warbler (Cardellina canadensis) In: Poole A (ed) The birds of North America online Ithaca: Cornell Lab of Ornithology. http://bna.birds.cornell.edu/bna/species/421/articles/introduction Accessed 20 March 2015

Riske ME (1976) Environmental impact upon grebes breeding in Alberta and British Columbia. PhD Thesis, University of Calgary, Calgary, AB

Robbins CS, Dawson DK, Dowell BA (1989) Habitat area requirements of breeding forest birds of the middle Atlantic states. Wildl Monogr 103: 1-34

Rockwell SM, Bocetti CI, Marra PP (2012) Carry-over effects of winter climate on spring arrival date and reproductive success in an endangered migratory bird, Kirtland's Warbler (Setophaga kirtlandii). The Auk 129: 744-752 
Salafsky N, Salzer S, Stattersfield AJ, Hilton-Taylor C, Neugarten R, Butchart SHM, Collen B, Cox N, Master LL, O’Connor S, Wilkie D (2008) A standard lexicon for biodiversity conservation: Unified classifications of threats and actions. Conserv Biol 22(4): 897-911

Schieck J, Hobson KA (2000) Bird communities associated with live residual tree patches within cut blocks and burned habitat in mixedwood boreal forests. Can J For Res 30: 1281-1295

Schieck J, Stuart-Smith K, Norton MR (2000) Bird communities are affected by amount and dispersion of vegetation retained in mixedwood boreal forest harvest areas. For Ecol Manag. 126: $239-254$

Schmiegelow FKA, Machtans CS, Hannon SJ (1997) Are boreal birds resilient to forest fragmentation? An experimental study of short-term community responses. Ecol 78: 19141932

Schneider R, Dyer S (2006) Death by a thousand cuts: Impacts of in situ oil sands development on Alberta's boreal forest. The Pembina Institute, Drayton Valley, AB

Schneider RJ, Stelfox BJ, Boutin S, Wasel S (2003) Managing the cumulative impacts of landuses in the western Canadian sedimentary basin: A modeling approach. Conserv Ecol 7(1) http://www.ecologyandsociety.org/vol7/iss1/art8/ Accessed 20 March 2015

Senate Subcommittee on the Boreal Forest (1999) Competing realities: The boreal forest at risk. Senate of Canada, Ottawa, ON. http://www.parl.gc.ca/content/sen/committee/361/bore/rep/ rep09jun99-e.htm Accessed 20 March 2015

Shaffer F, Laporte P (2003) Le Grèbe esclavon (Podiceps auritus) aux Îles-de-la- Madeleine: Population, nidification et habitat. Canadian Wildlife Service, Environmental Conservation Branch, Environment Canada, Québec, Quebec

Shell Canada Limited (2007) Application for approval of the Jackpine mine expansion project and Pierre river mine project, environmental assessment. Volume 5: Terrestrial resources and human environment. http://www.ceaaacee.gc.ca/050/documents_staticpost/59539/46923/volume 5.pdf Accessed 20 March 2015

Sillett TS, Holmes RT (2002) Variation in survivorship of a migratory songbird throughout its annual cycle. J Anim Ecol 71: 296-308

Sleep DJH, Drever MC, Szuba KJ (2009) Potential role of spruce budworm in range-wide decline of Canada Warbler. J Wildl Manag 73(4): 546-555

South Peace Bird Atlas Society (2006) Canada Warbler (Wilsonia canadensis). http://www.pris.bc.ca/spbas/index.htm Accessed 20 March 2015 
Stedman SJ (2000) Horned Grebe (Podiceps auritus) In: Poole A (ed) The birds of North

America online Ithaca: Cornell Lab of Ornithology.

http://bna.birds.cornell.edu/bna/species/505/ Accessed 20 March 2015

Steeger C, Hitchcock CL (1998) Influence of forest structure and diseases on nest-site selection by Red-breasted Nuthatches. J Wildl Manag 62(4): 1349-1358

Summers PD, Cunnington GM, Fahrig L (2011) Are the negative effects of roads on breeding birds caused by traffic noise? J Appl Ecol 48(6)

Therres GD, Byrd MA, Bradshaw DS (1993) Effects of development on nesting bald eagles:

Case studies from Chesapeake Bay. Trans N Am Wildl Nat Resour Conf 58: 62-69

Therriault TW, Hay DE, Schweigert JF (2009) Biologic overview and trends in pelagic forage fish abundance in the Salish Sea (Strait of Georgia, British Columbia). Mar Ornithol 37: 3-8

Thompson ID (2004) The importance of superior-quality wildlife habitats. The For Chron 80(1): $75-81$

Tittler R, Hannon SJ, Norton MR (2001) Residual tree retention ameliorates short-term effects of clear-cutting on some boreal songbirds. Ecol Appl 11: 1656-1666

Ulfvens J (1989) Clutch size, productivity and population changes in a population of the Horned Grebe Podiceps auritus in an exposed habitat. Ornis Fennica 66(2): 75-77

United States Geological Survey [USGS] (2007) USGS national wildlife health center, quarterly wildlife mortality report July 2006 to September 2006. http://www.nwhc.usgs.gov/ publications/quarterly_reports/2006_qtr_3.jsp Accessed 20 March 2015

United States Geological Survey [USGS] (2008) National wildlife health center, quarterly wildlife mortality report October 2007 to December 2007. http://www.nwhc.usgs.gov/publications/quarterly reports/2007 qtr 4.jsp Accessed 20 March 2015

Venier LA, Holmes SB, Pearce JL, Fournier RE (2012) Misleading correlations: The case of the Canada Warbler and spruce budworm. J Wildl Manag 76(2): 294-298

Vennesland RG (2010) Risk perception of nesting Great Blue Herons: Experimental evidence of habituation. Can J Zool 88: 81-89

Vermeer K, Cretney WJ, Elliott JE, Norstrom RJ, Whitehead PE (1993) Elevated polychlorinated dibenzodioxin and dibenzofuran concentrations in grebes, ducks, and their prey near Port Alberni, British Columbia, Canada. Mar Pollut Bull 26: 431-435

Wells J, Casey-Lefkowitz S, Chavarria G, Dyer S (2008) Danger in the nursery - Impact of birds of tar sands oil development in Canada's boreal forest. Natural Resources Defense Council, New York, NY 